\title{
A linear inversion method to infer exhumation rates in space and time from thermochronometric data
}

\author{
M. Fox ${ }^{1}$, F. Herman ${ }^{1, *}$, S. D. Willett ${ }^{1}$, and D. A. May ${ }^{1}$ \\ ${ }^{1}$ Institute of Geology, Swiss Federal Institute of Technology, ETH Zürich, Switzerland \\ *now at: Institute of Earth Science, University of Lausanne, Switzerland \\ Correspondence to: M. Fox (matthew.fox@erdw.ethz.ch)
}

Received: 1 June 2013 - Published in Earth Surf. Dynam. Discuss.: 19 July 2013

Revised: 19 December 2013 - Accepted: 8 January 2014 - Published: 28 January 2014

\begin{abstract}
We present a formal inverse procedure to extract exhumation rates from spatially distributed low temperature thermochronometric data. Our method is based on a Gaussian linear inversion approach in which we define a linear problem relating exhumation rate to thermochronometric age with rates being parameterized as variable in both space and time. The basis of our linear forward model is the fact that the depth to the "closure isotherm" can be described as the integral of exhumation rate, $\dot{e}$, from the cooling age to the present day. For each age, a one-dimensional thermal model is used to calculate a characteristic closure temperature, and is combined with a spectral method to estimate the conductive effects of topography on the underlying isotherms. This approximation to the four-dimensional thermal problem allows us to calculate closure depths for data sets that span large spatial regions. By discretizing the integral expressions into time intervals we express the problem as a single linear system of equations. In addition, we assume that exhumation rates vary smoothly in space, and so can be described through a spatial correlation function. Therefore, exhumation rate history is discretized over a set of time intervals, but is spatially correlated over each time interval. We use an a priori estimate of the model parameters in order to invert this linear system and obtain the maximum likelihood solution for the exhumation rate history. An estimate of the resolving power of the data is also obtained by computing the a posteriori variance of the parameters and by analyzing the resolution matrix. The method is applicable when data from multiple thermochronometers and elevations/depths are available. However, it is not applicable when there has been burial and reheating. We illustrate our inversion procedure using examples from the literature.
\end{abstract}

\section{Introduction}

Since the initial work of Clark and Jäger (1969) and Wagner and Reimer (1972), the potential for in situ thermochronometry to quantify exhumation rates through time has been widely recognized. According to the definition of closure temperature (Dodson, 1973), a thermochronometric age represents the time elapsed since a rock cooled through a specific temperature $\left(T_{\mathrm{c}}\right)$. Provided with an estimate of the thermal structure of the crust, a closure temperature can be related to a depth in Earth and a thermochronometric age used to calculate time-averaged exhumation rate (e.g., Clark and Jäger, 1969; England and Richardson, 1977). Therefore, a variety of thermochronometers and modeling techniques have gained a role in a range of geological research: from tectonic processes that build topography (Harrison et al., 1992; Batt and Braun, 1999; House et al., 1998; McQuarrie et al., 2005; Sutherland et al., 2009) to the erosional processes that destroys it (Schildgen et al., 2010; Shuster et al., 2011; Glotzbach et al., 2011). Furthermore, measurements of exhumation rate have fueled debate regarding how tectonics, climate and erosional processes interact to shape Earth's surface (Molnar and England, 1990; Willett and Brandon, 2002; Dadson et al., 2003; Valla et al., 2012; Glotzbach et al., 2011).

A variety of methods have been proposed to convert thermochronometric ages to exhumation rates. For example, a 
common approach is to collect and date a suite of samples distributed in elevation. If the samples exhumed together at a constant rate through a steady temperature field, the ages will show a linear relationship with elevation. The slope of this age-elevation relationship (AER) is equal to the exhumation rate and changes in slope can be interpreted as changes in exhumation rate through time (e.g., Wagner and Reimer, 1972; Wagner et al., 1979; Fitzgerald and Gleadow, 1988; Fitzgerald et al., 1995).

Thermal models have also been used to investigate exhumation rates. In this case, ages are calculated by tracking material paths through space and time and using the resulting temperature-time $(T-t)$ paths. Various analytical solutions have been presented to account for heat advection in response to erosion (e.g., Zeitler, 1985; Mancktelow and Grasemann, 1997; Brandon et al., 1998; Moore and England, 2001; Willett and Brandon, 2013) as well as the perturbation of the thermal field by topography (e.g., Lees, 1910; Birch, 1950; Stüwe et al., 1994; Mancktelow and Grasemann, 1997; Braun, 2002). Otherwise, numerical thermo-kinematic models have been used, in which spatial variations in rock uplift due to differential tectonic movements may be specified by structural or tectonic models combined with a surface erosion model (e.g., Grasemann and Mancktelow, 1993; Batt and Braun, 1997; Harrison et al., 1997; Batt and Braun, 1999; Stüwe and Hintermuller, 2000; Ehlers et al., 2003).

Measured and predicted ages can be compared through formal inverse methods. For example, two- and threedimensional thermal models have been combined with nonlinear inversion schemes, which minimize the difference between model predicted and measured ages. Using such an approach, the optimum exhumation rates may be inferred when exhumation rates, tectonics or topography vary as a function of time (e.g., Glotzbach et al., 2011; Campani et al., 2010; Herman et al., 2010; Braun et al., 2012). With these methods it is often necessary to solve the two- or three-dimensional thermo-kinematic model several thousand times, which can become computationally expensive.

An alternative to these computationally expensive threedimensional thermo-kinematic inverse models is to simply map spatial patterns in exhumation by converting isolated ages into time-averaged exhumation rates (e.g., Van den Haute, 1984; Omar et al., 1989; Brandon et al., 1998; Berger et al., 2008; Thomson et al., 2010). Vernon et al. (2008) computed the difference in elevation of isoage surfaces, which are interpolated from the data distributed in three dimensions, to estimate variations in exhumation rate. Alternatively, in a more sophisticated analysis Sutherland et al. (2009) implemented a nonlinear weighted least squares regression scheme for closure depth as a function of sample age. This approach enabled the authors to obtain a regional exhumation history, variable in space and time, for an application to ages from Fiordland, New Zealand.

In addition to inferring exhumation rates, complex cooling histories can be inferred from thermochronometric data. For example, the thermally controlled annealing of fission tracks provides constraints on $T-t$ paths between $\sim 110^{\circ} \mathrm{C}$ to $\sim 60^{\circ} \mathrm{C}$ for apatite (e.g., Green et al., 1985; Gleadow and Duddy, 1981; Green et al., 1989), and nonlinear inverse methods have been used to infer complex cooling and reheating histories (Gallagher, 1995, 2012; Willett, 1997; Ketcham et al., 2007). Gallagher et al. (2005) simultaneously exploited the variable $T-t$ information preserved in track length distributions from samples composing an AER. Due to the inclusion of the additional data from different elevations with different $T-t$ sensitivity, the resolution of the inferred $T-t$ history is greatly improved (Gallagher et al., 2005). Stephenson et al. (2006) investigated spatial and temporal variations in cooling rate using partition modeling to determine discrete spatial units with different thermal histories. However, the conversion of cooling rate to exhumation rate is not straightforward and requires a thermal model.

In this paper, we present a new method for estimating exhumation rates that are variable in both space and time. The key to our approach is to combine a general spacetime function for exhumation rate with a four-dimensional model of the temperature field. We simplify the kinematic problem by assuming that rock material follows a vertical path. The four-dimensional thermal field is approximated by a transient, one-dimensional thermal model, calculated independently at each data location. A temperature perturbation due to the conductive effects of the local surface topography is calculated. Although, with this formulation, each datum is treated independently, we link solutions by requiring that the exhumation rate function, and thus the temperature field, be spatially correlated and vary smoothly in space. This formulation permits even large data sets, consisting of ages from multiple thermochronometric systems distributed in both space and elevation, to be treated simultaneously and efficiently.

\section{Exhumation rates derived from thermochronometric ages co-located in space}

In this section, we derive the relationship between thermochronometric ages and exhumation rates for the case where multiple ages have been obtained from samples distributed in elevation but effectively co-located in the horizontal plane. This is the situation in which an AER is typically constructed. Note that due to the multiple variables mentioned in this section and the next, see Table 1 for a list of variables and where they are defined in the text.

\subsection{Forward and inverse formulations}

For an isolated thermochronometric age, the distance between the sample elevation and the elevation of the corresponding closure isotherm, $z_{\mathfrak{c}}$, can be described as the integral of exhumation rate, $\dot{e}$, from the present day to 
the thermochronometric age,

$\int_{0}^{\tau} \dot{e} \mathrm{~d} t=z_{\mathrm{c}}$,

where $\tau$ is the thermochronometric age. To obtain a numerical solution to this problem, we discretize the integral in Eq. (1),

$\sum_{j=1}^{M-1} \dot{e}_{j} \Delta t+\dot{e}_{M} R=z_{c}$

where $\dot{e}_{j}$ corresponds to the exhumation rate within a time interval of length $\Delta t . M$ is the number of time intervals and $R$ is the remainder of the division of $\tau$ by $M-1$, so that

$R=\tau-(M-1) \Delta t$.

In the case where two ages, $\tau_{1}$ and $\tau_{2}\left(\tau_{1}<\tau_{2}\right)$, are obtained from samples that are effectively co-located in space, but from different elevations, they will integrate over different time intervals of the same exhumation history. Therefore, Eq. (2) applies to each age, yielding two independent equations expressed in matrix form as

$\left[\begin{array}{cccccc}\Delta t & \cdots & \Delta t & R_{1} & 0 & 0 \\ \Delta t & \cdots & \cdots & \cdots & \Delta t & R_{2}\end{array}\right]\left[\begin{array}{c}\dot{e}_{1} \\ \vdots \\ \vdots \\ \dot{e}_{M_{1}} \\ \vdots \\ \dot{e}_{M_{\max }}\end{array}\right]=\left[\begin{array}{c}z_{c_{1}} \\ z_{c_{2}}\end{array}\right]$,

where $M_{\max }$ is the number of time intervals sampled by the oldest age, $\tau_{2}$, and $\dot{e}_{M_{\max }}$ is the exhumation rate during this time interval.

For the general case of $N$ samples, we express Eq. (4) as

$\mathbf{A} \dot{\mathbf{e}}=\mathbf{z}_{\mathrm{c}}$,

where $\mathbf{A}$ is the forward model matrix ${ }^{1}$ and has dimensions $N \times M_{\max }, \dot{\mathbf{e}}$ is a vector containing the exhumation rates over each time interval and has length $M_{\max }$, and $\mathbf{z}_{\mathrm{c}}$ is a vector of length $N$ containing the set of differences between sample elevation and elevation of the closure isotherm. Recognizing that $z_{\mathrm{c}}$ is an observation with some uncertainty, $\epsilon$, Eqn. 5 is only an exact equation by including this uncertainty explicitly:

$\mathbf{A} \dot{\mathbf{e}}+\boldsymbol{\epsilon}=\mathbf{z}_{\mathrm{c}}$.

The unknown quantity in this matrix equation is $\dot{\mathbf{e}}$ and its estimation requires solving the linear inverse problem. In

\footnotetext{
${ }^{1}$ Henceforth, bold lower case variables will denote vectors and bold upper case variables will denote matrices.
}

Table 1. Variables and location of definition in the text.

\begin{tabular}{|c|c|c|}
\hline Variable & Definition & Defined \\
\hline$z_{\mathrm{c}}$ & Closure depth & Eq. (1) \\
\hline$\dot{e}$ & Exhumation rate & Eq. (1) \\
\hline$\tau$ & Thermochronometric age & Eq. (1) \\
\hline$\Delta T$ & Time interval length & Eq. (2) \\
\hline$M$ & Number of discrete time intervals & Eq. (2) \\
\hline$R$ & Remainder of $\tau / \Delta T$ & Eq. (3) \\
\hline$M_{\max }$ & Maximum number of discrete time intervals & Eq. (4) \\
\hline$N$ & Number of ages & Eq. (5) \\
\hline $\mathbf{A}$ & Forward model matrix & Eq. (5) \\
\hline$\epsilon$ & Uncertainty on closure depth & Eq. (6) \\
\hline$\sigma_{\mathrm{pr}}^{2}$ & a priori variance & Eq. (7) \\
\hline $\mathbf{C}$ & Model parameter covariance matrix & Eq. (7) \\
\hline $\mathbf{C}_{\epsilon}$ & Data covariance matrix & Eq. (8) \\
\hline$\dot{\mathbf{e}}_{\mathrm{po}}$ & a posteriori exhumation rate & Eq. (9) \\
\hline$\dot{\mathbf{e}}_{\mathrm{pr}}$ & a priori exhumation rate & Eq. (9) \\
\hline $\mathbf{C}_{\mathrm{po}}$ & a posteriori covariance matrix & Eq. (8) \\
\hline $\mathbf{R}$ & Model resolution matrix & Eq. (12) \\
\hline$T$ & Temperature & Eq. (14) \\
\hline$\kappa$ & Thermal diffusivity & Eq. (14) \\
\hline$T_{\mathrm{m}}$ & Mean temperature with depth & Eq. (15) \\
\hline$T_{\mathrm{d}}$ & Temperature perturbation due to topography & Eq. (15) \\
\hline$q_{l}$ & Basal heat flux & Eq. (17) \\
\hline$k_{l}$ & Thermal conductivity & Eq. (17) \\
\hline$t^{*}$ & Onset of exhumation & Eq. (17) \\
\hline$T_{\mathrm{c}}$ & Closure temperature & Sect. 2.2 \\
\hline$z_{\mathrm{m}}$ & Closure depth with respect to $\mathrm{z}=0$ & Sect. 2.2 \\
\hline$h$ & Sample elevation & Sect. 2.2 \\
\hline$\psi^{2}$ & Misfit criterion & Eq. (19) \\
\hline$\rho(u)$ & Spatial correlation & Eq. (21) \\
\hline$u$ & Separation distance & Eq. (21) \\
\hline$\phi$ & Length scale parameter & Eq. (21) \\
\hline$h(x, y)$ & Earth surface topography & Sec. 3.3 \\
\hline$p(x, y)$ & Isotherm topography with respect to $z_{\mathrm{m}}$ & Sect. 3.3 \\
\hline$\gamma_{a}$ & Atmospheric lapse rate & Sect. 3.3 \\
\hline$\gamma$ & General geothermal gradient as a function of depth & Sect. 3.3 \\
\hline$\zeta$ & Continuation factor & Eq. (24) \\
\hline
\end{tabular}

the case where $M_{\max }$ is greater than $N$, the problem is nonunique. Even if $N$ is greater than $M_{\max }$, the calculations of Eq. (6) will rarely be independent, so we must use formal inverse methods for underdetermined or mixed-determined problems. We use a method of linear Gaussian inversion in which both the unknowns (i.e., model parameters) and data are described as stochastic, or random, variables that have a Gaussian probability density characterized by a mean and a variance. Using this approach requires some a priori knowledge of the model parameters in order to construct a covariance matrix for the model parameters (Backus and Gilbert, 1968, 1970; Jackson, 1972; Tarantola and Valette, 1982).

In our case, the stochastic variables are the exhumation rate and the errors on the closure depth. Therefore, we define an a priori exhumation rate model that is independent of the data and consists of an estimate of the mean exhumation rate, $\dot{e}_{\mathrm{pr}}$, and an estimate of the variance about this mean, $\sigma_{\mathrm{pr}}^{2}$. This variance is used to construct the model parameter covariance matrix, $\mathbf{C}$, which has dimensions $M_{\max } \times M_{\max }$ and diagonal 
elements equal to the a priori variance $\sigma_{\mathrm{pr}}^{2}$ :

$C_{i j}=\sigma_{\mathrm{pr}}^{2} \delta_{i j}, \quad i, j \in\left[1, M_{\max }\right]$,

where $\delta_{i j}$ is the Kronecker delta. Off-diagonal elements of $\mathbf{C}$ are equal to zero as we assume exhumation rates are not correlated in time. We then use the estimate of data errors, $\boldsymbol{\epsilon}$, to describe the data covariance matrix, $\mathbf{C}_{\epsilon}$, with dimensions $N \times N$. In our problem, the errors in the system come from analytical errors in the ages, $\varepsilon_{i}$, and from uncertainty in how this relates to a closure depth. If the errors are uncorrelated, the data covariance matrix is diagonal, with components

$\left(C_{\epsilon}\right)_{i j}= \begin{cases}\dot{e}_{\mathrm{pr}} \varepsilon_{i} & \text { if } i=j \\ 0 & \text { if } i \neq j\end{cases}$

Given this formulation of the model parameter and data covariance matrices and the a priori estimate of the model parameters, the underdetermined problem has a maximum likelihood estimate of the model parameters (Franklin, 1970; Tarantola, 2005):

$\dot{\mathbf{e}}_{\mathrm{po}}=\dot{\mathbf{e}}_{\mathrm{pr}}+\mathbf{C A}^{T}\left(\mathbf{A C A} \mathbf{A}^{T}+\mathbf{C}_{\epsilon}\right)^{-1}\left(\hat{\mathbf{z}}_{\mathrm{c}}-\mathbf{A} \dot{\mathbf{e}}_{\mathrm{pr}}\right)$,

where $\dot{\mathbf{e}}_{\mathrm{pr}}$ is a vector of length $N$ containing the $\dot{e}_{\mathrm{pr}}$. The model parameter estimate, $\dot{\mathbf{e}}_{\mathbf{p o}}$, is the maximum likelihood estimate or the a posteriori exhumation rate. It is also treated as a Gaussian variable with a covariance matrix, $\mathbf{C}_{\mathbf{p o}}$, which provides a measure of the uncertainty on the parameter estimate with respect to the a priori variance and is calculated as

$\mathbf{C}_{\mathrm{po}}=\mathbf{C}-\mathbf{H A C}$

where the diagonal elements of $\mathbf{C}_{\mathrm{po}}$ show the a posteriori variance, $\sigma_{\mathrm{po}}^{2}$, and $\mathbf{H}$ is the inverse operator from Eq. 9:

$\mathbf{H}=\mathbf{C} \mathbf{A}^{T}\left(\mathbf{A C A} \mathbf{A}^{T}+\mathbf{C}_{\epsilon}\right)^{-1}$.

One advantage of linear inverse methods is that one can estimate the resolution of the inferred model parameters. The model resolution matrix, $\mathrm{R}$

$\mathbf{R}=\mathbf{H A}$,

provides a measure of this resolution. This resolution matrix gives information on how well the estimate of the model parameters correspond to the true parameters, and is a function of the age distribution and age uncertainty. $\mathbf{R}$ relates the difference between the a priori and a posteriori exhumation rates to the difference between the a priori and the actual, or true model parameters, $\dot{\mathbf{e}}_{\text {true }}$, through

$\dot{\mathbf{e}}_{\mathrm{po}}-\dot{\mathbf{e}}_{\mathrm{pr}}=\mathbf{R}\left(\dot{\mathbf{e}}_{\text {true }}-\dot{\mathbf{e}}_{\mathrm{pr}}\right)$.

If the resolution is perfect, $\dot{\mathbf{e}}_{\mathrm{po}}-\dot{\mathbf{e}}_{\mathrm{pr}}$ is equal to $\dot{\mathbf{e}}_{\text {true }}-\dot{\mathbf{e}}_{\mathrm{pr}}$. Perfect resolution is obtained when the resolution matrix is equal to the identity matrix. In this instance, the exhumation rates inferred for a specified time interval are resolved independently of exhumation rates in other time intervals. The further $\mathbf{R}$ is from the identity matrix, the less resolved the model parameters are.

\subsection{Computation of closure depth}

Deriving an exhumation rate from thermochronological data requires information on the depth to the closure temperature. This can be achieved by solving the heat transfer equation:

$\frac{\partial T}{\partial t}-\dot{e} \frac{\partial T}{\partial z}=\kappa \nabla^{2} T$,

where $T(x, y, z, t)$ is the temperature, $t$ is time, $\dot{e}$ is the exhumation, and $\kappa$ is the thermal diffusivity. Heat production is not explicitly included. However, as we calibrate model heat flow to measured surface heat flow, the contribution of heat production to near-surface geothermal gradients is accounted for. The surface boundary condition is the fixed temperature of the Earth's surface and there is a basal condition reflecting the deep Earth heat flux.

For the thermochronometry problem the two effects we need to consider are perturbation of the isotherms by surface topography and vertical advection of heat by surface erosion and the upward motion of rock. We deal with each of these separately by decomposing the thermal field into two components (Turcotte and Schubert, 1982): an average temperature, $T_{\mathrm{m}}$, which varies with depth and time, and a perturbation away from this mean induced by the topography, $T_{d}$,

$T(x, y, z, t)=T_{\mathrm{m}}(z, t)+T_{\mathrm{d}}(x, y, z, t)$.

The one-dimensional problem to solve for the mean temperature with depth is described by the simpler form of the heat equation:

$\frac{\partial T_{\mathrm{m}}}{\partial t}-\dot{e} \frac{\partial T_{\mathrm{m}}}{\partial z}=\kappa \frac{\partial^{2} T_{\mathrm{m}}}{\partial z^{2}}$,

which we solve using a finite difference method in space. The solution in time is obtained using a Crank-Nicolson time integration. We use an integration time step that provides a Courant-Friedrichs-Lewy number of $\sim 1$ to ensure accuracy. The upper surface for the thermal model, $z=0$, is chosen as the average elevation, with respect to sea level, of the area covered by the data and the temperature at this elevation is $T_{0}$. The boundary conditions are thus,

$\left\{\begin{array}{l}\left.\frac{\left.\partial T_{\mathrm{m}}\right)}{\partial z}\right|_{z=l}=\frac{q_{l}}{k_{l}} \\ \left.T_{\mathrm{m}}\right|_{z=0}=T_{0},\end{array}\right.$

where $l$ is the depth to the base of the model, $q_{l}$ is the heat flow into the base of the model, and $k_{l}$ is the thermal conductivity. The initial condition for the problem (i.e., at time $\left.t^{*}\right)$ is a constant geothermal gradient, and we run the model from some assumed time of initiation of exhumation until the present day. 
The next step consists of deriving the closure temperature and its corresponding closure depth from the thermal model. The closure temperature depends on the cooling rate at the time of closure (Dodson, 1973). We use kinetic parameters for the Dodson equation from the literature: helium diffusion in apatite (Farley, 2000), fission track annealing in apatite (Ketcham et al., 1999) and helium diffusion in zircon (Reiners et al., 2004). For an exhuming rock, the appropriate cooling rate is obtained from a transient geotherm through the material derivative:

$$
\frac{D T_{\mathrm{m}}}{D t}=\frac{\partial T_{\mathrm{m}}}{\partial t}+\dot{e} \frac{\partial T_{\mathrm{m}}}{\partial z} .
$$

This cooling rate is then used to predict the closure temperature. With a transient geotherm $T_{\mathrm{m}}(t, z)$, cooling rate is a function of depth and time, but for any given time, there is a single depth where the temperature and the closure temperature are equal (Fig. 1). The distance traveled by a rock from this depth to the surface is the closure depth and is equal to $z_{\mathrm{m}}+h$, where $h$ is the elevation of the sample with respect to the mean elevation.

In order to calculate $T_{\mathrm{m}}(t, z)$, and thus cooling rate and closure temperature, we require the exhumation rate. This is unknown and is the quantity that we are trying to obtain. This defines a nonlinear problem in $\dot{e}$, which we solve by direct iteration of Eq. (6). Fortunately, for most exhumation rates, this nonlinearity is weak and necessitates only a few iterations. We initialize the problem by using the a priori value for the exhumation rate, $\dot{e}_{\mathrm{pr}}$.

\subsection{Age elevation profile}

The inversion scheme outlined above is now illustrated with a vertical age profile, where the AER can be easily interpreted. We use published apatite fission track (AFT) data from samples collected within the footwall of the Denali Fault, taken from Fitzgerald et al. (1995) (Fig. 2). These data show a break in slope of the AER, which can be interpreted as a change in exhumation rate. Our aims are to assess how well we can resolve this apparent change in exhumation rate and to determine the dependencies of our inferred exhumation rates on (1) the time interval length, $\Delta t$; (2) the thermal parameters; and (3) the a priori model for the exhumation rate. To assess the quality of fit of the predicted to the observed ages for the different models, we report a misfit criterion, $\psi^{2}$, defined as

$\psi^{2}(\dot{\mathbf{e}})=\sqrt{\frac{1}{N} \sum_{i=1}^{N}\left(\frac{\tau_{\text {pred }, i}-\tau_{i}}{\epsilon_{i}}\right)^{2}}$,

where predicted ages, $\tau_{\text {pred }}$, are calculated from the $T-t$ paths using Dodson's expression, as described above. In the examples below we present the misfit values for the ages using both the a priori and a posteriori model parameters. These

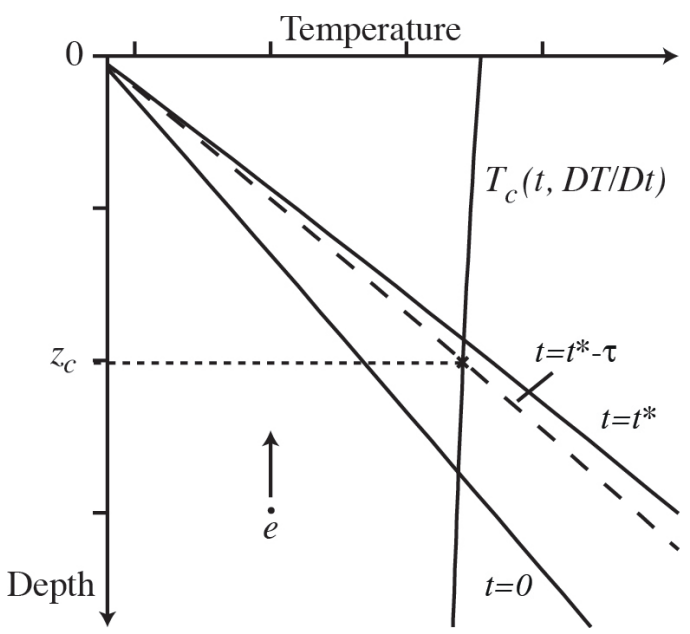

Figure 1. The evolution of crustal temperature through time in the presence of erosion rate at a rate of $\dot{e}$. Closure temperature, $T_{\mathrm{c}}$, is shown at time $t^{*}-\tau$ (Dodson, 1973). The initial geotherm $(t=0)$ has a constant gradient. A cooling age of $\tau$ records closure at a time of, $t=t^{*}-\tau$, and a depth of, $z_{\mathrm{c}}$.

are designated $\psi_{\mathrm{pr}}^{2}$ and $\psi_{\mathrm{po}}^{2}$, respectively. The difference between these numbers provides a quantitative measure of the model fit relative to the fit provided by a model with a constant exhumation rate.

We first describe results of a reference inverse model and then develop subsequent models by systematically varying parameterizations and a priori assumptions.

\subsubsection{Reference inverse model}

We start this reference model at a time equal to $25 \mathrm{Ma}$ and discretize the exhumation history into time intervals, $\Delta t$, of $2.5 \mathrm{Myr}$. All elevations and depths are calculated with respect to a mean elevation of $4020 \mathrm{~m}$. The thermal boundary condition is also fixed at this elevation, which is held at a temperature of $-12{ }^{\circ} \mathrm{C}$. We assume an a priori exhumation rate of $0.5 \pm 0.15 \mathrm{~km} \mathrm{Myr}^{-1}$. The initial geothermal gradient is $24^{\circ} \mathrm{C} \mathrm{km}^{-1}$. With a constant exhumation rate of $0.5 \mathrm{~km} \mathrm{Myr}^{-1}$, the present day surface geothermal gradient would be $38.9^{\circ} \mathrm{C} \mathrm{km}^{-1}$. Values for other parameters used in the reference model are shown in Table 2.

Solving Eq. (9) for the age data shown in Fig. 2 gives the exhumation estimate shown in Fig. 3. The solid line gives the inferred exhumation rate and the grey shaded region gives this rate plus or minus one standard deviation, which we obtain as the square root of the diagonal terms of the a posteriori covariance matrix, Eq. (10). The a posteriori data misfit, $\psi_{\mathrm{po}}^{2}$, is smaller than the a priori misfit, $\psi_{\mathrm{pr}}^{2}$, reflecting the improved data fit.

The inversion results reveal that prior to the closure of the oldest age $(17 \mathrm{Ma})$ we have only the a priori information, and the data have no influence on the a posteriori exhumation 
Table 2. Parameters used to determine reference inverse model for the Denali Fault in Sect. 2.3.1.

\begin{tabular}{lll}
\hline Parameter & Value & Units \\
\hline$h_{\mathrm{m}}$ & 4020 & $\mathrm{~m} . \mathrm{a} . \mathrm{s} .1$ \\
$T_{0}$ & -12 & ${ }^{\circ} \mathrm{C}$ \\
$q_{l}$ & 76 & $\mathrm{~mW} \mathrm{~m}^{-2}$ \\
$\kappa$ & 30 & $\mathrm{~km}^{2} \mathrm{Myr}^{-1}$ \\
$k_{l}$ & 2.6 & $\mathrm{Wm}^{-1} \mathrm{~K}^{-1}$ \\
$l$ & 80 & $\mathrm{~km}$ \\
$t^{*}$ & 25 & $\mathrm{Ma}$ \\
$\Delta t$ & 2.5 & $\mathrm{Myr}$ \\
$\bar{e}_{\mathrm{pr}}$ & 0.5 & $\mathrm{~km} \mathrm{Myr}^{-1}$ \\
$\sigma_{\mathrm{pr}}$ & 0.15 & $\mathrm{~km} \mathrm{Myr}$ \\
\hline
\end{tabular}

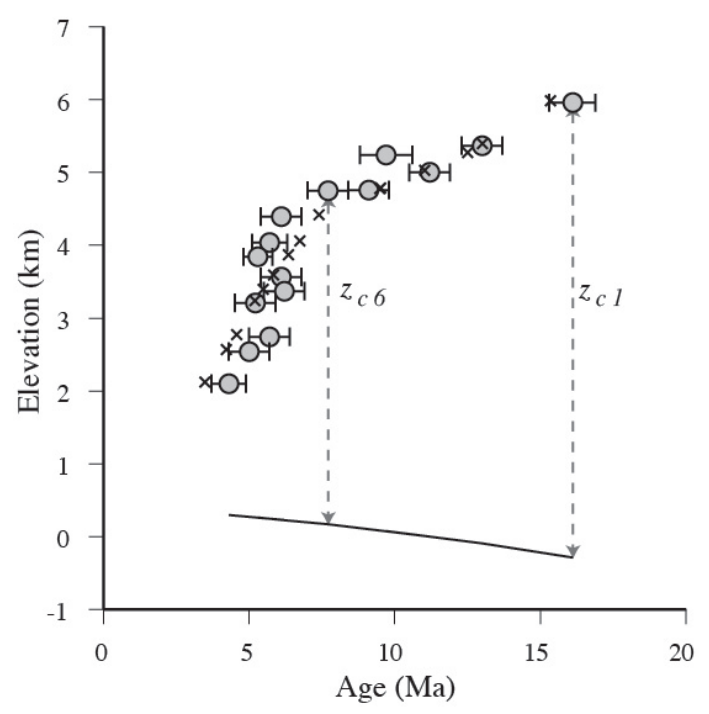

Figure 2. Apatite fission track ages from Mount Denali (Fitzgerald et al., 1995) plotted as a function of elevation. There is a break in slope at $6 \mathrm{Ma}$, interpreted as a response to an increase in exhumation rate. The lower curve shows the evolution of the closure depth through time in response to changes in the geotherm, as discussed in the text. Also plotted are the predicted ages (crosses) using the exhumation rate history shown in Fig. 3 b.

rate. For these time intervals, the a posteriori variance is equal to the a priori variance, indicating that the data have no influence on the a posteriori rate. Subsequently, the cooling ages resolve a slow exhumation rate (with reduced variance) of about $\sim 0.2 \mathrm{~km} \mathrm{Myr}^{-1}$ from 15-7.5 Ma and a high rate of $0.6 \mathrm{~km} \mathrm{Myr}^{-1}$ from $7 \mathrm{Ma}$ to the present day.

During the iterative process the computed closure temperatures and closure depths evolve subject to the exhumation rate. As shown in Fig. 4, the computed closure temperatures and closure depths with respect to the mean elevation remain constant after three iterations.

It is also important to establish the resolution of the inferred exhumation rate history. To this end, we calculate and show the resolution matrix R, Eq. (12), in Fig. 5a. It shows
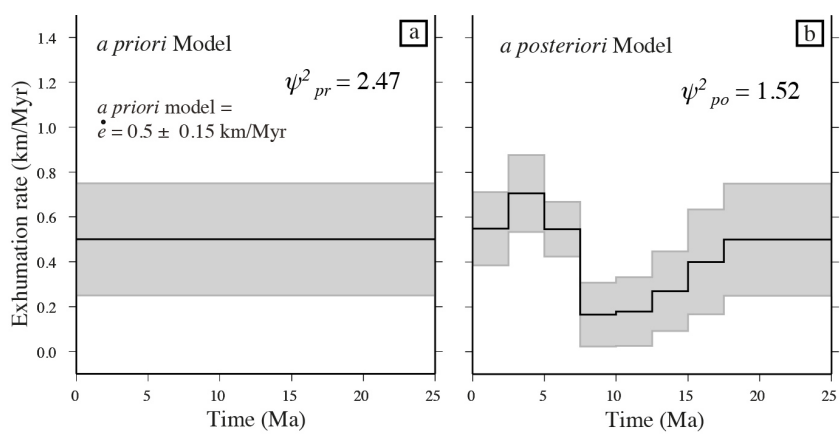

Figure 3. (a) The a priori exhumation rate and (b) the a posteriori exhumation rate, which is variable in time. Grey envelopes indicate one standard deviation in the a priori or a posteriori exhumation rate. Also given are a norm of the misfit values to the ages using the a priori model and the a posteriori model, $\psi_{\mathrm{pr}}^{2}$ and $\psi_{\mathrm{po}}^{2}$, respectively.

that parameters relating to the early stages of the model (25-22.5 to $20-17.5 \mathrm{Ma}$ ) are unresolved, indicated by values of zero in the upper left-hand block of the matrix. This is expected as there are no age data within these time intervals. The exhumation rate from 17.5 Ma to the present is partiallyto-fully resolved by the data, reflected by the range of the measured ages. The highest value of resolution is the diagonal element of the matrix corresponding to the time interval of 7.5-5 Ma. This corresponds to the high gradient segment of the AER, so that there are several ages within this interval constraining its exhumation rate. This is also reflected in the near zero values of the off-diagonal components of this row of the matrix. The most recent phase of exhumation, from 5 to $0 \mathrm{Ma}$, includes two time intervals (last two rows of the resolution matrix). No ages fall into this time interval, and the exhumation rate for these two intervals is not well-resolved, as indicated by the near equal values of the four lower-right components of the resolution matrix. This shows that the exhumation rate between $5 \mathrm{Ma}$ and the present cannot be resolved into two independent time intervals.

A further measure of parameter resolution is provided by assessing the covariance between model parameters. The full posterior covariance matrix provides that information. We scale covariance by the diagonal entries of the posterior covariance matrix to assess the correlation, thereby providing a correlation parameter that varies from -1 to 1 . We convert covariance between two parameters, $\xi$ and $\beta$, denoted $C_{\xi \beta}$, to correlation between these parameters $\hat{C}_{\xi \beta}$ (Tarantola, 2005):

$\hat{C}_{\xi \beta}=\frac{C_{\xi \beta}}{\sqrt{C_{\xi \xi}} \sqrt{C_{\beta \beta}}}$.

The complete correlation matrix is shown in Fig. 5b. Correlation values along the diagonal part of the correlation matrix (Fig. 5b) are equal to 1. Off-diagonal elements are dominated by negative values, indicating that the uncertainties are anti-correlated, which implies that exhumation rate parameters have not been independently resolved by the data. 

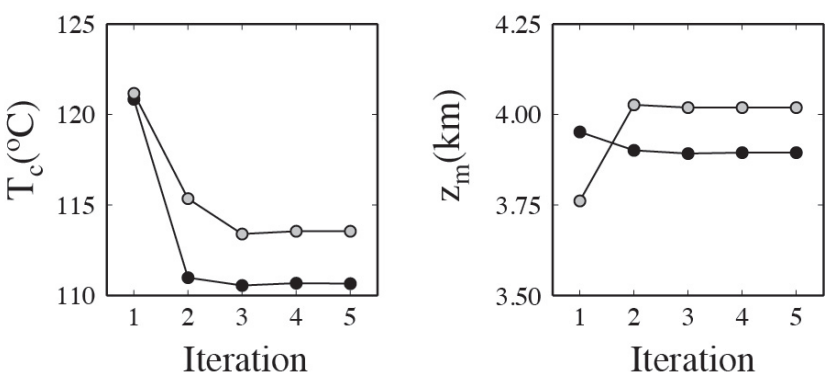

Figure 4. Evolution of closure temperature and closure depth during the iterative process. The black circles show a sample collected from high in the vertical profile with an age of $9.2 \mathrm{Ma}$. The grey circles show a sample from lower elevations with an age of 5.2 Ma. Both ages show that after three iterations closure temperature and closure depths remain constant during the iteration process.

Anti-correlation is also expected: if two time intervals are available to exhume a rock from a given depth, by increasing the exhumation rate during one interval, the rate during the other interval is required to decrease. In the early stages of the model (25-22.5 to 20-17.5 Ma), the correlation matrix suggests that the model parameters are perfectly resolved. However, this is because the a posteriori covariance matrix is equal to the a priori covariance matrix, which is diagonal. In the time intervals younger than $17.5 \mathrm{Ma}$, the relative importance of negative off-diagonal elements is lowest during the 7.5-5 Ma time interval as this parameter has the highest resolution. Conversely, the off-diagonal elements during more recent exhumation, from 5 to $0 \mathrm{Ma}$, have values close to minus one. These large negative values demonstrate that the most recent phase of exhumation is unresolved.

\subsubsection{Effect of the time interval length}

The inferred exhumation rates vary with the selection of the time interval length, $\Delta t$. Figures $6 \mathrm{~d}$ and $6 \mathrm{~g}$ show inversion results where the time interval length has been changed relative to the reference model. In the case of shorter time intervals (Fig. 6d), the a posteriori standard deviation of the exhumation rate is generally larger than that of the reference model in Figure 6a. The exhumation history is also more poorly resolved. In spite of the fact that there is more generality to the exhumation rate history, the data misfit is increased and $\psi_{\mathrm{po}}^{2}$ is slightly higher compared to Fig. 6d. This is because, by having shorter, less well resolved time intervals, deviations from the a priori value are reduced and changes in exhumation rate are smoothed. Finally, the timing of the change from slow exhumation to fast exhumation is approximately $7 \mathrm{Ma}$. This age of increased exhumation rate is very similar to age of the break in slope of the AER (see Fig. 2).

With longer time interval length the a posteriori standard deviation of the exhumation rate is reduced. This is because there are fewer model parameters and, therefore, fewer possible exhumation rate histories that could fit the data. However,

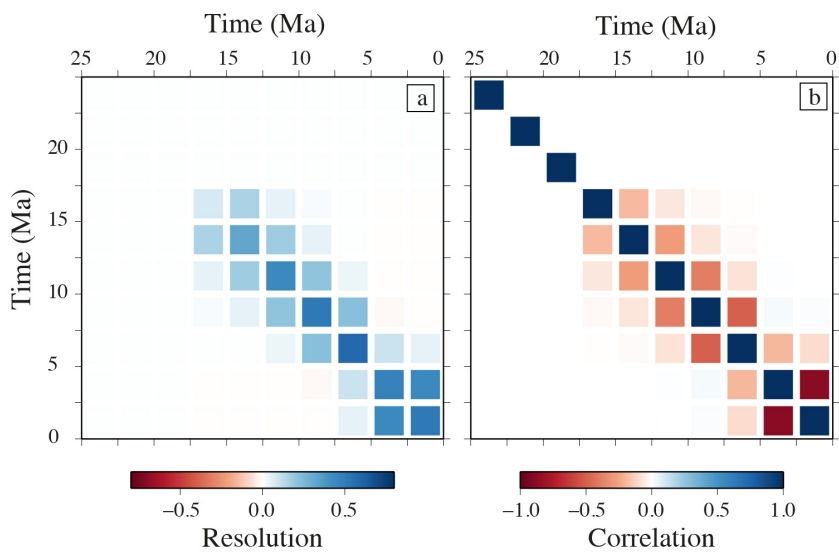

Figure 5. The model resolution matrix (a) and the correlation matrix (b) for the inversion shown in Fig. 3. Each element in these matrices relates exhumation rate during one time interval to exhumation rate during a different time interval. Large positive values of the diagonals of the resolution matrix indicate well-resolved parameters.

$\psi_{\mathrm{po}}^{2}$ is larger than for the reference model. This is due to the fact that the long time intervals changes in exhumation rate may not be possible at the appropriate time. For example, the time interval 10-5 Ma spans the break on slope ( $7 \mathrm{Ma})$ and therefore the data fit is reduced.

The diagonal elements of the resolution matrices provide information about how well resolved exhumation rates are through time. For the reference model, a maximum resolution value is found for the time interval of 7.5-5 Ma (and is $\sim 0.6$ ). With shorter time intervals, exhumation rates are not resolved independently of one another and the maximum value is only 0.3 . Conversely, with long time intervals the maximum resolution value is 0.97 for the time interval 5$0 \mathrm{Ma}$, indicating that this parameter is almost perfectly resolved.

This example highlights the trade-off between model complexity and variance reduction or parameter resolution. A greater number of time intervals permits greater variability and thus the precise timing of changes in exhumation rate to be identified. However, variance reduction and parameter resolution are decreased, indicating that model parameters are not resolved independently.

\subsubsection{Effect of the thermal model}

The assumptions made for the thermal model calculations have important implications for the estimated exhumation rates. In the case of a single age, the exhumation rate depends directly on the depth to the closure isotherm. Any error in the thermal model translates directly into an error of the exhumation rate estimate. Multiple ages provide a redundancy that partially overcomes this effect, but sensitivity to the thermal model remains. This is highlighted by the in- 
version results shown in Fig. 6h and 6i. In these models, the thermal parameters were selected such that the initial geothermal gradients are $18.6^{\circ} \mathrm{C} \mathrm{km}^{-1}$ and $29.3^{\circ} \mathrm{C} \mathrm{km}^{-1}$, respectively, compared to the reference model, which has a gradient of $24{ }^{\circ} \mathrm{C} \mathrm{km}^{-1}$. In each case, we observe that when the exhumation rate is constrained by the vertical separation between two ages, the a posteriori exhumation rate estimate changes little. However, exhumation rates during the most recent stages vary widely, depending on the thermal model. For example, the inferred exhumation rate during the final time interval is $0.4 \mathrm{~km} \mathrm{Myr}^{-1}$ for the case in which the surface geothermal gradient is relatively high (Fig. 6i), compared to $0.8 \mathrm{~km} \mathrm{Myr}^{-1}$ for the case with a low gradient (Fig. 6h).

\subsubsection{Effect of changes in the a priori exhumation rate}

The a priori exhumation rate includes the expected value (mean) of exhumation rate and its variance. First, we investigate the effect of changing the a priori variance, which acts as a penalty parameter. A lower variance forces the inverse solution to attain a value close to the a priori value of exhumation rate. Conversely, a higher a priori variance permits more variation in the inverse solution, resulting in a better fit to the data. This is shown in Fig. $6 b$ and $c$ where the a priori variance is decreased and increased compared to the reference inverse model (Fig. 6a), respectively. With a lower a priori variance, a smoother solution is obtained as model parameters are penalized more strongly for deviations away from the a priori value. On the other hand, a large a priori variance (Fig. 6c) produces larger variations in the a posteriori model parameters. In addition, the a priori variance has an important effect on the a posteriori variance. Therefore, in order to interpret the a posteriori variance as parameter uncertainty it is important to compare it to the a priori variance.

Second, we explore the effect of the a priori mean exhumation rate on the parameter estimation. The cases in which the a priori exhumation rate is lower and higher are shown in Fig. 6e and f, respectively. In these models, the time intervals with no age constraints (17-25 Ma) simply have the a priori value of exhumation rate. However, once the ages constrain the exhumation rate, the a priori value has little influence on the a posteriori exhumation rate. It is also worth noting that we use the a priori exhumation rate to calculate the evolution of the thermal model, which explains the observed differences in exhumation rates in Fig. 6a, e and f.

\section{Inversion of spatially distributed data}

Here we extend the previous analysis to account for thermochronometric data that are spatially distributed and therefore have the potential to resolve spatial variability in exhumation rate. We illustrate the methodology with a case study using topography and published data from the Dabie Shan, China.

\subsection{Correlation in Space}

We include spatial variability in exhumation rate by describing exhumation rate as a spatial stochastic process. As a spatial stochastic process, a variable is described by not only a mean value and a variance but also by a spatial covariance. We thus define the covariance of exhumation rate, $\mathbf{C}$, as a spatial process with a spatial correlation function. The correlation function describes how exhumation rates vary in space. We define this as a function of the separation distance, $u$ :

$\rho(u)=\exp \left(-(u / \phi)^{k}\right)$

where $\phi$ is a length scale parameter, and the function is a Gaussian function when $k=2$ and an exponential function when $k=1$.

\subsection{Inverse Problem}

The inversion process is constructed in the same manner as outlined for the co-located samples. However, we now define an independent exhumation history for each sample but require that exhumation rate varies smoothly in space through the spatial correlation function. Hence, exhumation rate, $\dot{\mathbf{e}}$, has length $M_{\max } N$ and the forward model operator, $\mathbf{A}$, has size $N \times M_{\max } N$. The covariance matrix now contains the spatial correlation structure between the exhumation rates defined in Eq. (21) (Tarantola and Nercessian, 1984; Willett, 1990). For a single time interval, a block of the covariance matrix is constructed using the separation distance between the $i$ th and $j$ th data $(u)$ and the correlation function, $\rho(u)$ :

$\mathbf{C}_{i j}=\sigma_{\mathrm{pr}}^{2} \delta_{i j} \rho(u)$

It is assumed that exhumation rate is not correlated in time, so there is an independent matrix of form Eq. (22) for each time interval. These can be combined into a global matrix, setting cross time interval terms to zero.

Aside from this change in definition of the covariance matrix, the inversion process and the definition of the inverse operator, Eq. 9, remain unchanged. The a posteriori covariance matrix contains information about how inferred rates covary in time and space. The resolution matrix contains information about which parameters are determined independently of one another in time and space.

We have introduced a new model parameter, the characteristic length scale, $\phi$. Its value can either be prescribed in a way to give a desired spatial smoothing, or it can be estimated through geostatistical methods (e.g., Matheron, 1963). The value of $\phi$ provides a means to trade-off model smoothness against variance reduction. A smaller $\phi$ reduces the number and weight of age data used to infer exhumation rates at any given location. A larger $\phi$ provides more spatial smoothing.

Finally, for ease of visualization and interpretation, we evaluate exhumation rate at arbitrary points defined on a regular grid. The exhumation rate at an arbitrary location is a 


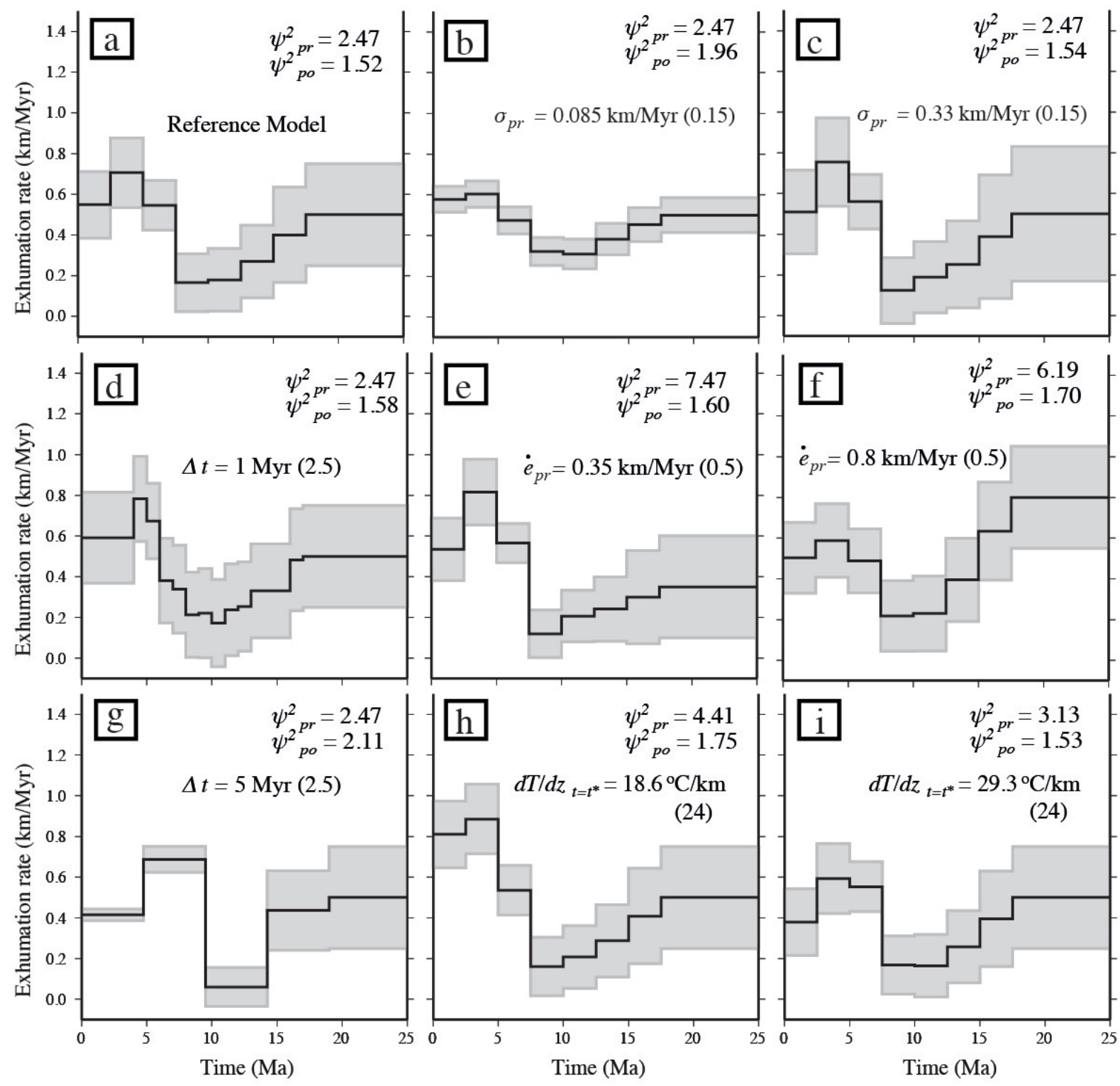

Figure 6. Exhumation rates inferred from age data from Fitzgerald et al. (1995) for different a priori model parameters. (a) Reference model; (b-i) independent analyses with one parameter changed with respect to the reference model, as indicated. The corresponding parameter value in the reference model is shown in brackets.

weighted average of the exhumation rates evaluated at the data locations. Here the relative weights are defined by the separation distances between the data locations and the point of interest and the correlation function imposed in the inversion.

The resolution matrix still relates the estimated and true values of exhumation rate but now includes temporal and spatial relationships. As a consequence, $\mathbf{R}$ is difficult to visualize. To simplify, we integrate the resolution values across the spatial dimension for each time interval. An integrated value of one corresponds to an exhumation rate that is resolved independently of other time intervals.

\subsection{The effects of topography on a closure isotherm}

In Sec. 2.2 we calculated the depth to a closure isotherm from a one-dimensional model that assumed an isothermal boundary condition at the mean topographic elevation. However, if we are to extend the analysis to investigate exhumation rates across a larger region, the topography of Earth's surface needs to be included (Lees, 1910; Bullard, 1938; Jeffreys, 1938; Birch, 1950; Werner, 1985).

Variations in elevation of Earth's surface as well as variations in the surface temperature imply a complex threedimensional thermal boundary condition. We take an approach that simplifies this problem by reducing surface 
topography and surface temperature to perturbations of temperature on a horizontal plane located near the Earth's surface. This temperature perturbation at the surface can then be propagated downwards to a specific depth, $z_{\mathrm{m}}$. In turn the perturbation in temperature at a specific depth can be converted to a perturbation in depth of an isotherm (Turcotte and Schubert, 1982; Stüwe et al., 1994; Mancktelow and Grasemann, 1997).

In Eq. (15) we decomposed the temperature field into two components, a mean temperature that varies with depth, $T_{\mathrm{m}}$, and a perturbation from this mean, $T_{\mathrm{d}}$. Mancktelow and Grasemann (1997) derive an expression to calculate temperature perturbations at depth due to a cosine temperature perturbation at the surface in the presence of heat advection. In our notation this expression is

$\left.T_{\mathrm{d}}(\lambda, z)\right|_{z=z_{\mathrm{m}}}=\left.\exp \left(\zeta z_{\mathrm{m}}\right) T_{\mathrm{d}}(\lambda, z)\right|_{z=0}$,

where $\left.T_{\mathrm{d}}(\lambda, z)\right|_{z=0}$, is a cosine function with known wavelength, $\lambda$, and $\zeta$ is defined as

$\zeta=-\left(\frac{\dot{e}}{2 \kappa}+\sqrt{\left(\frac{\dot{e}}{2 \kappa}\right)^{2}+(2 \pi k)^{2}}\right)$,

where $k$ is the wave number $(1 / \lambda)$.

However, the depth perturbation of a closure isotherm is required and not simply the temperature perturbation at a specific depth calculated from the thermal model, $T_{\mathrm{m}}$, as in Sect. 2.2. As closure depth evolves through time due to the advection of heat, the mean closure depth for each thermochronometric system is used to calculate a perturbation for each system.

The elevation of the surface of the model is chosen as the mean elevation of the area covered by the analysis. A temperature perturbation at this elevation is a function of the projection of the surface temperature (surface topography and atmospheric lapse rate) and the local geothermal gradient (Bullard, 1938; Jeffreys, 1938),

$\left.T_{\mathrm{d}}(\lambda, z)\right|_{z=0}=-h(\lambda)\left(\gamma_{0}-\gamma_{a}\right)$,

where $h(\lambda)$ is cosine function representing Earth's topography and $\gamma_{a}$ is the atmospheric lapse rate. $\gamma_{0}$ is the geothermal gradient at $z=0$ taken from the transient mean thermal model, $T_{\mathrm{m}}$, and the specific time in the past.

Similarly, the temperature perturbation at a mean closure depth, $z_{\mathrm{m}}$, can be written in terms of the isotherm topography and the geothermal gradient at that depth, $\gamma_{z_{\mathrm{m}}}$ :

$\left.T_{\mathrm{d}}(\lambda, z)\right|_{z=z_{\mathrm{m}}}=-p(\lambda) \gamma_{z_{\mathrm{m}}}$,

where $p(\lambda)$ is the perturbation of the closure isotherm about $z_{\mathrm{m}}$. At this point we have expressions for $T_{\mathrm{d}}$ at $z=0$ as a function of the topography that can be easily calculated, and $T_{\mathrm{d}}$ at $z=z_{\mathrm{m}}$ as a function of the topography of a closure isotherm. These expressions, Eq. (26) and Eq. (25), can be combined in

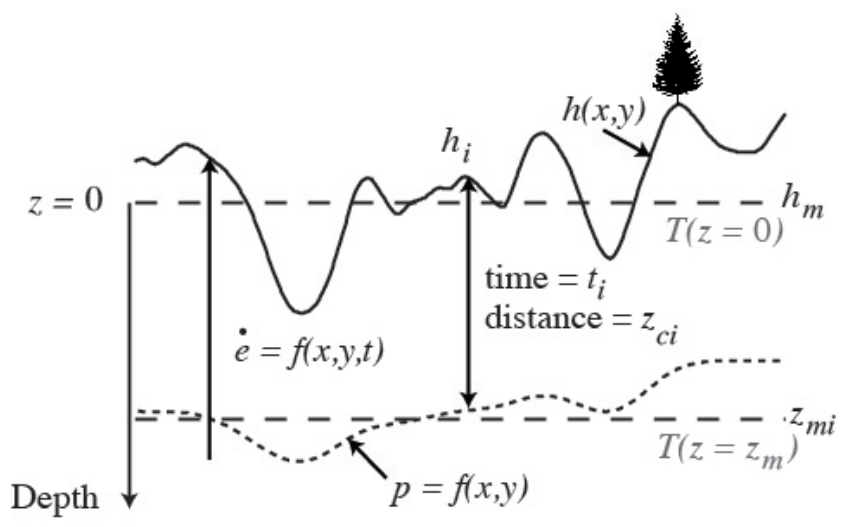

Figure 7. Surface topography, $h$, and a closure isotherm, $p$. The mean elevation, $h_{\mathrm{m}}$, is defined relative to sea level, but subsequent depths and elevations are taken from this datum, thus defined to be $z=0$. The mean closure depth $z_{\mathrm{m} i}$, calculated for a specific age $i$, is shown as long dashed line, and $p$ is the closure isotherm. An age, $\tau$, from elevation, $h_{i}$, records the time taken to exhume from the closure depth, $z_{\mathfrak{c} i}$.

Eq. (23) to give the perturbation of closure depth. The resulting expression for a specific wavelength of the topography, $h(\lambda)$, is

$p(\lambda)=A_{0} \exp \left(\zeta z_{\mathrm{m}}\right) h(\lambda)$

where $A_{0}$ contains the atmospheric lapse rate and geothermal gradients evaluated from $T_{\mathrm{m}}$,

$A_{0}=\left(\frac{\gamma_{0}-\gamma_{a}}{\gamma_{z_{\mathrm{m}}}}\right)$.

Finally, as any complex topography in one or two dimensions can be described as a infinite sum of periodic functions, and the principle of superposition applies, this analysis can be extended to account for any topography. We calculate $p(x, y)$ in the frequency domain (e.g Ducruix et al., 1974; Blackwell et al., 1980; Blakely, 1996). The distance to a closure isotherm for a single age is given by

$\left(z_{\mathrm{c}}\right)_{i}=\left(z_{\mathrm{m}}\right)_{i}-p_{i}+h_{i}$

where $p_{i}$ is the value of $p(x, y)$ at the spatial location of the age, as illustrated in Fig. 7.

\section{Case study from the Dabie Shan, SE China}

We illustrate the ability of our inversion procedure to resolve spatially variable exhumation rates based on data from the Dabie Shan in southeastern China, Fig. 8. The Dabie Shan is a $200 \mathrm{~km}$ wide mountain belt with subdued relief. The last major phase of tectonics was during the early to middle Cretaceous. Reiners et al. (2003) reported ages from a vertical transect at the core of the range and from isolated samples collected around the flanks of the range, using three thermochronometric systems, (U-Th)/He ages from 

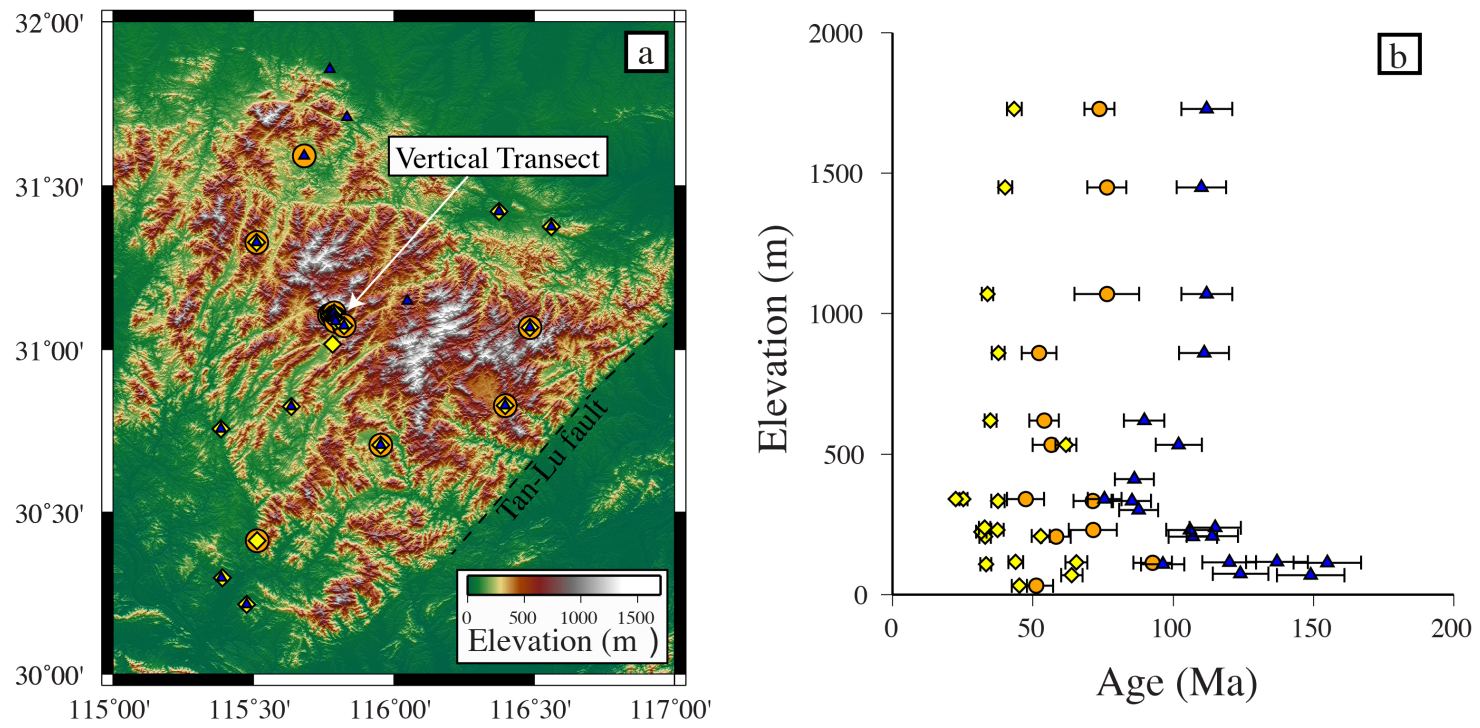

Figure 8. (a) Topographic map of the Dabie Shan, SE China, showing zircon (U-Th)/He, apatite fission track and apatite (U-Th)/He ages in blue triangles, orange circles and yellow diamonds, respectively, from Reiners et al. (2003). (b) The ages plotted as a function of elevation.

zircon (ZHe) and from apatite (AHe), and AFT dating (Reiners et al., 2003). The ages across the region show a positive AER in the core of the range and older ages around the flanks (Reiners et al., 2003). They concluded that exhumation rate has been slow, $0.06 \pm 0.01 \mathrm{~km} \mathrm{Myr}^{-1}$, since the Cretaceous, with a possible increase in exhumation rate (up to $0.2 \mathrm{~km} \mathrm{Myr}^{-1}$ ) between 80-40 Ma. There appear to be few tectonic structures responsible for this observed pattern of cooling ages, suggesting decay of old topography. Braun and Robert (2005) attributed the exhumation pattern to an isostatic response of relief reduction in the core of the range.

We use the Dabie Shan topography and data distribution to demonstrate and validate two key components of our inversion methodology: first, the approximation for the influence of topography on a closure isotherm; and second, the importance of the correlation structure of the parameter covariance matrix. As a test of the inversion scheme, before applying the algorithm to the measured ages, we apply the analysis to a suite of known synthetic ages produced with a thermokinematic model.

\subsection{Example of the closure isotherm approximation}

We use the topography of the Dabie Shan to demonstrate how the perturbation of a closure isotherm is calculated. The mean closure depths for $\mathrm{AHe}$ and $\mathrm{ZHe}$ are estimated from a onedimensional thermal model representative of the Dabie Shan, $T_{\mathrm{m}}$. The upper boundary of the thermal model is set at the average elevation, inferred from SRTM data (Farr et al., 2007), over the region shown in Fig. 9, 149.1 m.a.s.l.; the temperature at this elevation is set and held at $14.1^{\circ} \mathrm{C}$. Other parameters used in the thermal model are defined in Table 3. This initial model results in geothermal gradient of $22.7^{\circ} \mathrm{C} \mathrm{km}^{-1}$, which increases to $25.3^{\circ} \mathrm{C} \mathrm{km}^{-1}$ after $120 \mathrm{Myr}$ of erosion at $0.06 \mathrm{~km} \mathrm{Myr}^{-1}$.

From $T_{\mathrm{m}}$ we obtain the average values for the parameters required to calculate the closure isotherms, Table 4.

The topography with respect to the mean elevation of the area is shown in Fig. 9a. The two-dimensional discrete Fourier transform of the topography is computed using standard methods (e.g., Press et al., 1992) and we compute $p(x, y)$ in the frequency domain. The perturbation of the closure isotherms of $\mathrm{AHe}$ and $\mathrm{ZHe}$ about the mean closure depths are shown in Fig. $9 \mathrm{~b}$ and 9c, respectively.

\subsection{Testing the closure isotherm approximation}

The analytical method for calculating the topographic effects on isotherm depth involve a number of approximations, foremost of which is the conversion of the Earth's surface into a temperature perturbation on a flat plane. To compare the perturbation of an isotherm about a mean depth, we initially calculate a value for the mean depth and temperature, as in Sect. 2.2. We also calculate $T_{\mathrm{m}}$ by applying a constant temperature at depth $900{ }^{\circ} \mathrm{C}$ at $z=31.5 \mathrm{~km}$ so that the models are compatible. We evaluate a mean closure depth using $T_{\mathrm{m}}$ for AHe closure at the mean age of AHe ages, $\tau^{\mathrm{AHe}}=40.9 \mathrm{Ma}$, at a temperature of $57.44^{\circ} \mathrm{C}$. To test our approximation for the thermal structure of the crust we generate a three-dimensional thermal field, using a finite-element solution to the advection-conduction equation, Pecube (Braun, 2003). Using identical thermal parameters and the topographic surface, the depth of the $57.44{ }^{\circ} \mathrm{C}$ isotherm is calculated using the three-dimensional thermal model and the 
Table 3. Parameters used to calculate the temperature field for the Dabie Shan, as described in Sect. 4.1.

\begin{tabular}{cll}
\hline Parameter & Value & Units \\
\hline$h_{\mathrm{m}}$ & 149.1 & m.a.s.l \\
$T_{0}$ & 14.1 & ${ }^{\circ} \mathrm{C}$ \\
$\kappa$ & 35 & $\mathrm{~km}^{2} \mathrm{Myr}^{-1}$ \\
$k_{l}$ & 2.6 & $\mathrm{Wm}^{-1} \mathrm{~K}^{-1}$ \\
$l$ & 51.5 & $\mathrm{~km}$ \\
$t^{*}$ & 120 & $\mathrm{Ma}$ \\
$\overline{\dot{e}}_{\mathrm{pr}}$ & 0.08 & $\mathrm{~km} \mathrm{Myr}$ \\
\hline
\end{tabular}

method presented in Sect. 3.3. The misfit in depth between the isotherms calculated with the two different approaches is small, $-1.68 \mathrm{~m}$.

\subsection{Testing resolution of the data}

In this section, we conduct a resolution test to see how well the data from the Dabie Shan could be expected to resolve a spatially variable exhumation pattern. This test is made by generating synthetic age data from a known exhumation function, then analyzing these data with our inversion scheme in order to see how well the known exhumation rates are recovered. The procedure provides a confirmation of our inversion algorithm, but is primarily a test of the resolving capability of the Dabie Shan data number and location.

Synthetic ages are produced by integrating the temperature along material paths in the 3-D finite-element code Pecube (Braun, 2003). We specify a vertical velocity with an exhumation rate of $0.07 \mathrm{~km} \mathrm{Myr}^{-1}$ within a rectangular region in the center of the model domain and $0.05 \mathrm{~km} \mathrm{Myr}^{-1}$ outside of this rectangle. We predict AHe, AFT and ZHe ages with the Dodson approximation, at the same spatial locations as in Reiners et al. (2003). We assign the same measurement errors as in the reported data.

For the inversion analysis, we used an a priori exhumation rate of $0.06 \mathrm{~km} \mathrm{Myr}^{-1}$ with an a priori standard deviation of $0.02 \mathrm{~km} \mathrm{Myr}^{-1}$. We used an exponential spatial correlation function with a length scale parameter of $28 \mathrm{~km}$, although we investigate the effects of this parameter later. The time interval length for the model is $30 \mathrm{Myr}$. We use the same thermal parameters and boundary conditions as were used to generate the synthetic ages.

Figure 10 shows the resulting inferred exhumation rates. Results are shown for each of the four time intervals of the inverse model. During the time interval from $120 \mathrm{Ma}$ to $90 \mathrm{Ma}$, only the oldest ages influence the estimate of the exhumation rate and these are all found in the peripheral, slowexhumation rate region. We normalize the a posteriori variance by the a priori variance as this provides a measure of the information content of the data. A normalized variance value of one and a temporal resolution value of zero highlights where the model is not resolved. The normalized a
Table 4. Parameters used to calculate closure isotherms for the Dabie Shan, as described in Sect. 2.3.1.

\begin{tabular}{llll}
\hline Parameter & $\begin{array}{l}\text { ZHe } \\
\text { value }\end{array}$ & $\begin{array}{l}\text { AHe } \\
\text { value }\end{array}$ & Units \\
\hline$z_{\mathrm{m}}$ & 6.4 & 1.7 & $\mathrm{~km}$ \\
$T_{\mathrm{c}}$ & 167.1 & 56.3 & ${ }^{\circ} \mathrm{C}$ \\
$\gamma(0, t)$ & 24.0 & 25.2 & ${ }^{\circ} \mathrm{C} \mathrm{km}^{-1}$ \\
$\gamma\left(z_{\mathrm{m}}, t\right)$ & 23.7 & 25.1 & ${ }^{\circ} \mathrm{C} \mathrm{km}^{-1}$ \\
\hline
\end{tabular}

posteriori variance and the temporal resolution show that the solution is poorly resolved during this time interval.

From 90-60 Ma, there are also age data within the block of fast exhumation rate, and near these data, the exhumation rate is partially resolved, as indicated by the reduction of the a posteriori variance and the increase of temporal resolution. By 60-30 Ma, the exhumation rate is resolved and accurately estimated; however, due to the smoothness imposed in the model covariance matrix, the distinct boundaries of the block are "blurred". This pattern is also observed in the final time interval, 30-0 Ma; however, the exhumation rates are slightly lower than the true values in the core of the block. Where there is an absence of data, for example in the southeast corner, the exhumation rate never deviates from the a priori value and shows a normalized variance close to one, whereas values of temporal resolution remain close to zero, as shown in Fig. 10.

The blurred nature of the result is due to the smooth correlation function used for the parameter covariance matrix. With additional ages located close to the boundaries of the block, we would be more likely to resolve this discrete step in exhumation rate.

As a further complication, it is evident that the blurring in space during one time interval also influences the entire exhumation rate history for the region. The exhumation rate during the oldest time interval demonstrates this effect. During this time interval there are only ages where the exhumation rate is slow. These slow rates are correctly inferred outside of the block, but are also inferred within the block. The degree to which exhumation rate outside of the block depends on exhumation rate within the block is a function of the correlation scale, and secondarily of the a priori variance; the larger the a priori variance, the easier it is for distant data to influence the result.

In addition, as this spatial averaging results in a low estimate of exhumation rate in the block, the advective heat transport and geothermal gradients are also underestimated and closure depths overestimated. This effect is similar to the example shown in Sect. 2.3.3.

\subsection{Effect of the correlation function}

As the imposed correlation function influences our results, we test two covariance functions as well as the correlation 


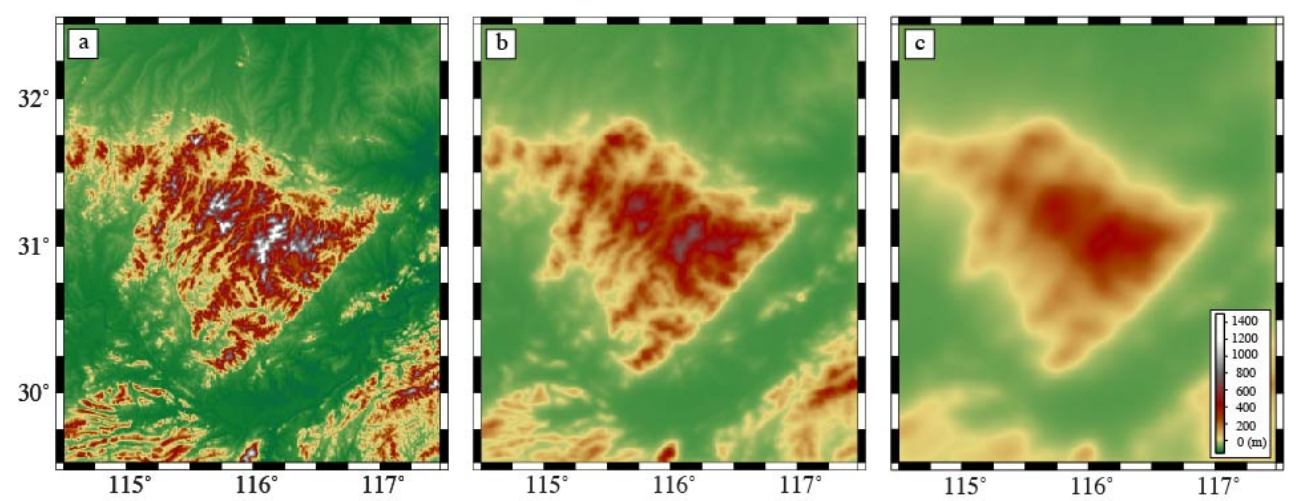

Figure 9. (a) The surface topography of Dabie Shan, (b) the topography of the closure isotherm for the AHe system and (c) the topography of the closure isotherm for the ZHe system. The isotherms are plotted as perturbations about the mean closure depths for the two systems. Refer to Sect. 3.3 and Sect. 4.1 for a full description.

length scale parameter, Eq. (21). Figure 11 shows how the a posteriori misfit, $\psi_{\mathrm{po}}^{2}$, changes as a function of the correlation length scale, $\phi$. Two correlation functions are used, an exponential function and a Gaussian function. If the correlation length, $\phi$, is low, in the extreme this becomes equivalent to inverting each age independently with no ability to average out noise in the data or to identify changes in exhumation rate through time. Furthermore, deviations of the a posteriori rate from the a priori exhumation rate are suppressed (see Fig. 11). In contrast, when $\phi$ is large, samples which record different exhumation rates are forced to correlate and so an overly smooth exhumation pattern is obtained, as can be seen in Fig. 11.

\subsection{Exhumation history of the Dabie Shan}

We now apply our method to the measured ages of Reiners et al. (2003). As with the synthetic data, the model is initiated at $120 \mathrm{Ma}$ and the exhumation history is discretized into $30 \mathrm{Myr}$ time intervals. The a priori exhumation rate is $0.08 \pm 0.03 \mathrm{~km} \mathrm{Myr}^{-1}$ based on Al-in-hornblende geobarometer estimates of intermediate calc-alkaline plutons and orthogneisses from within the Dabie Shan (Ratschbacher et al., 2000). Our thermal model predicts an increase of surface geothermal gradients from the initial value at the onset of exhumation, $22^{\circ} \mathrm{C} \mathrm{km}^{-1}$ to the present day value of $25^{\circ} \mathrm{C} \mathrm{km}^{-1}$ through time (Hu et al., 2000). The closure depths are calculated as described in Sect. 4.1. Prior to about $115 \mathrm{Ma}$, exhumation rates were very high, $\sim 2 \mathrm{~km} \mathrm{Myr}^{-1}$ (Liu et al., 2010), and may have perturbed the thermal regime, but we assume that this effect does not influence the late thermal history (Ratschbacher et al., 2000). We impose a correlation length scale parameter of $\phi=28 \mathrm{~km}$.

Estimated exhumation rates in space and time are shown in Fig. 12. During the time interval of $120-90 \mathrm{Ma}$, there is low spatial resolution due to the limited number of old ages (see Fig. 12). At the eastern end of the range (where the ages are oldest), exhumation rates of $\sim 0.09 \mathrm{~km} \mathrm{Myr}^{-1}$ are resolved, as indicated by the low a posteriori variance. In the core of the range, the exhumation rates are slightly lower, $\sim 0.07 \mathrm{~km} \mathrm{Myr}^{-1}$. The north and south flanks of the range are not well resolved, as indicated by the high normalized variance and low resolution values.

From 90-60 Ma we see high exhumation rates (> $0.1 \mathrm{~km} \mathrm{Myr}^{-1}$ ) near the Tan-Lu Fault, and a gradual decrease towards the northwest, possibly supporting activity on this fault during this time interval (Grimmer et al., 2002). The northeastern extent of the range continues to exhume at $\sim 0.09 \mathrm{~km} \mathrm{Myr}^{-1}$.

The time interval from $60-30$ Ma shows slower exhumation rates at the front of the range close to the Tan-Lu fault, in agreement with Reiners et al. (2003). There is also a decrease in exhumation rate in the eastern region. In contrast, we observe a slight increase in the core of the range. This pattern of exhumation rate, with the core of the range exhuming faster than the flanks, is consistent with an isostatic response to a decrease in relief and reduction of topography.

During the final time interval of exhumation, 30-0 Ma, a similar structure as in the previous time interval is inferred, with the core of the range exhuming faster than the flanks. However, the magnitude of the exhumation rates has reduced, most noticeably in the core of the range from $\sim 0.08$ to $\sim 0.06 \mathrm{~km} \mathrm{Myr}^{-1}$.

\section{Discussion}

We have presented a method for deriving time and spatially variable exhumation rates based on a collection of thermochronometric ages from different systems, locations and elevations. The analysis can be regarded as an extension of age-elevation plots in that it capitalizes on the different distances traveled by rocks at the surface of high relief topography with respect to closure depth. In addition, by combining ages obtained from different thermochronomet- 


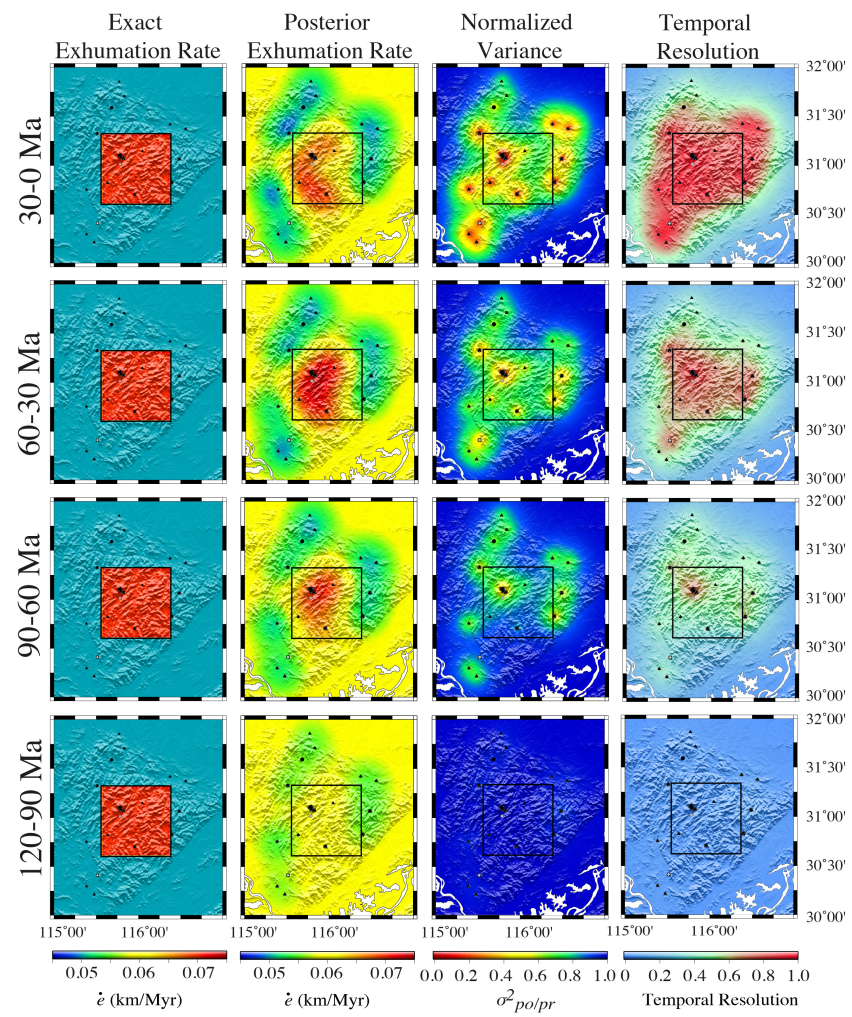

Figure 10. Results of the inversion of synthetic data with locations at the black points; thermochronometric system of each datum is consistent with the measurements of Reiners et al. (2003). Each row corresponds to a different time interval. The red boxes in the left column define a region with an exhumation rate of $0.07 \mathrm{~km} \mathrm{Myr}^{-1}$; background rate is $0.05 \mathrm{~m} \mathrm{Myr}^{-1}$. The second column shows exhumation rates inferred through inversion of these data. The third column shows the parameter variances normalized by the a priori variance. The right column displays the temporal resolutions.

ric systems, we resolve cooling rates in time by fitting the travel time between closure isotherms as well as final cooling to the surface.

The innovation of our method is that it combines many of the common methods of analyzing thermochronometric ages to derive exhumation rate. Least-squares fitting of ages distributed in elevation, thermal modeling of depth between closure temperatures for different mineral systems, and thermal modeling of individual ages can all be considered subsets of our analysis method. The problem with many of these traditional methods is that one must assume that all the ages distributed across a landscape have a common exhumation history, which is often not the case. Here we address this problem explicitly by imposing a spatial correlation, thereby requiring a common exhumation history only for points within a distance defined by a correlation length scale.

A major assumption of our method is that the kinetics of all thermochronometers are governed by a linear first order Arrhenius process, which enables us to use Dodson's ap-

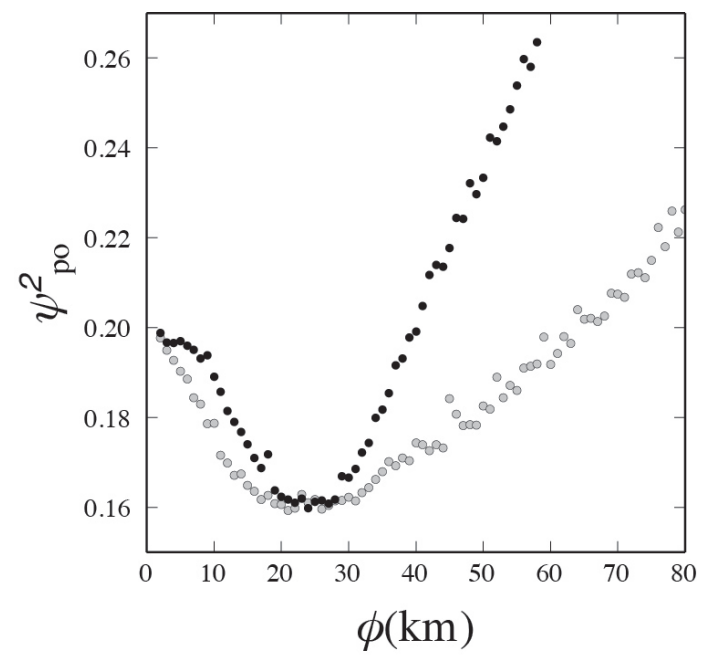

Figure 11. Sum of the squared misfit between predicted and observed ages as a function of the correlation length scale, $\phi$. The gray circles show the results assuming an exponential correlation function $(k=1$, Eq. (21)); the black circles use a Gaussian correlation function $(k=2$, Eq. (21)).

proximation to estimate the depth of closure. However, a large body of work shows that the kinetics of AFT or AHe can become nonlinear due to effects such as radiation damage or multi-compositional annealing (Carlson et al., 1999; Ketcham et al., 1999, 2007; Shuster et al., 2006; Flowers et al., 2009). Fortunately, expanding the use of Dodson's parameters to represent the kinetics of closure can still include some of these complexities. For example, where compositional information is available for AFT ages, specific populations of ages can be modeled with specific sets of kinetic parameters. In this case, retentive apatites and non-retentive apatites would be modeled with separate kinetic parameters and thus closure temperatures. Similarly, grain size or radiation damage in (U-Th)/He ages can be accounted for by redefining the corresponding first order kinetic parameters (Reiners and Brandon, 2006; Shuster et al., 2006). In the extreme case, defining specific kinetic parameters independently for each measured age is possible and would require no modifications to our method as defined here.

In certain scenarios the linear assumption may break down. As a result, the uncertainties associated with the inferred exhumation rates may not be Gaussian, and the resulting parameter correlations may be more complex than reported. This is a common limitation of linear inverse methods, and a nonlinear method may be more appropriate in scenarios where the full range of models consistent with thermochronometric data are required. The linear assumption would be particularly restrictive if the extremes in parameter values were required. However, we expect nonlinear effects to be small over the parameter range we are interested in. 


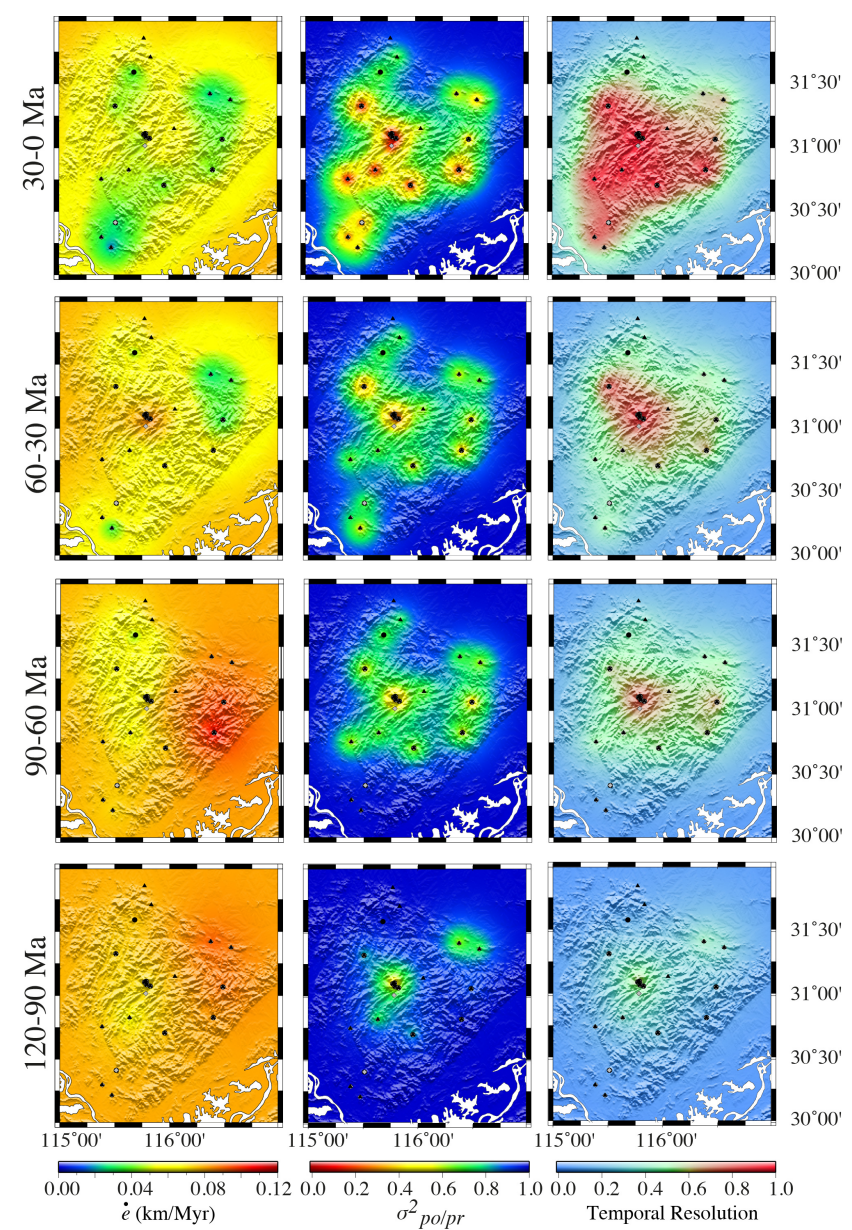

Figure 12. Exhumation rate history of the Dabie Shan. The left column shows the a posterior exhumation rates, the center column shows the a posteriori variances normalized by the a priori variance, and the right-hand column shows the temporal resolutions.

Our method is best used for regional studies where the exhumation history is relatively simple. This is, first, because we assume that rocks only experienced monotonic cooling, implying that complex reheating has not occurred. Second, exhumation rates are smooth in space and are not strongly affected by surface-breaking faults. This latter complication can be easily accounted for, where these are wellidentified, by building them into the correlation structure. In such cases, samples from either side of a fault could follow independent exhumation histories. In scenarios where ages record complex cooling and reheating histories, our approach would not be suitable because Dodson's approximation is invalid. Fortunately, complex cooling histories can be identified through additional information such as the analysis of fission track length distributions (Gallagher, 1995; Willett, 1997; Ketcham et al., 2007; Gallagher et al., 2005).

The thermal model, although simpler than solving a full three-dimensional problem, includes the major components

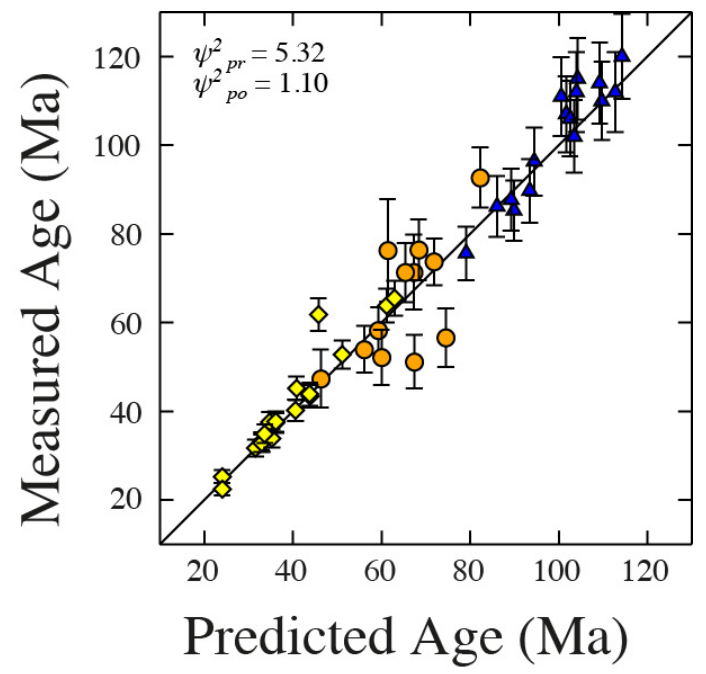

Figure 13. Comparison between model-predicted ages and measured ages. The solid black line is the $1: 1$ line. The error bars are the reported standard deviation of the measured ages.

of heat transfer necessary to solve this problem (i.e., conduction and advection). This combined with a spectral method enables us to include the effects of topography on the shape of underlying isotherms. It should be successful in most cases, but it might fail in regions of very high relief or very high exhumation rates where the approximation of topography into temperatures on a plane might not be accurate. Furthermore, where exhumation rate is described by 2- or 3-D kinematics, our methodology may be less successful. For example, orogens with high rates of horizontal displacement, which is associated with large scale thrust faulting, should be treated with caution. Our implementation could lead to an apparent change in exhumation rate in time, which would correspond to a change in the trajectory of rocks traveling through an orogenic wedge or up a thrust ramp. Likewise, the thermal model that we have implemented will not account for exhumation in situations where extensional unroofing dominates, unless it is very shallow.

The choice of initial and boundary conditions on the thermal model can have significant implications on the nearsurface geothermal gradient and, therefore, the estimated exhumation rates. Although we have demonstrated the inference is robust when good age-elevation data exist or several thermochronometric systems are available, the thermal model can have a significant impact on the exhumation rates during the latest stages of exhumation. In this case, the thermal model will entirely control the distance the rock has to travel from its closure isotherm to the surface over the time defined by its thermochronometric age. It is therefore important to test several models using different initial and boundary conditions and assess how robust the estimated exhumation rates are. 
One of the advantages of the formal inversion we adopt is in the ability to assess noise propagation from data to model parameters and to establish resolution. As the results of the analysis vary due to changes in the imposed parameterization and thermal model, shown in Fig. 6, the inferred exhumation rate uncertainty (obtained from the a posteriori covariance matrix) does not reflect the true model uncertainty. Therefore, a range of models with different imposed parameterization are required to convey the true uncertainty. We focus on interpreting the resolution in time; spatial resolution can be inferred from the spatial distribution of an age data set. It is computed, by definition, using the data error and parameter covariance matrices and, in our case, integrated spatially. It indicates how well exhumation rates at each time interval can be resolved independently of exhumation rate in other time intervals. The examples we report clearly show that resolution degrades back in time, which implies that we are more likely to resolve more recent exhumation rates and their variations.

As the problem as we have defined it is underdetermined, we require additional information to determine exhumation rate. This is in the form of a mean exhumation rate, $\dot{e}_{\mathrm{pr}}$, and an expected variance about this mean, $\sigma^{2}$ (along with a model for spatial covariance for the spatial case). In the majority of cases the a priori exhumation rate is an estimate of the average exhumation rate derived from any available information, although in principle it should be independent of the thermochronometric data. This could be in the form of sediment flux into neighboring sedimentary basins, geodetic derived rock uplift rates, or paleo-barometry estimates. Additional complexities, in the form of spatial and temporal variations, could be built into the a priori exhumation rate. However, where data exhibit good elevation distributions, results are relatively independent of the a priori exhumation rate.

For the spatial case, the parameter covariance matrix we implement largely controls the spatial resolution. It is defined through a correlation length scale and an a priori variance on the a priori exhumation rates. It serves as a tradeoff parameter, trading solution resolution in space against the need to average out noise and to combine ages from different elevations or with different closure temperatures in order to resolve exhumation rates in time. Therefore, it is key to choose a correlation length scale that is appropriate. In most cases, it can be defined using statistical methods, for example, through the computation of a semi-variogram (e.g., Matheron, 1963). Similarly, the a priori variance must be chosen carefully. Its primary influence is as a weighting factor for the data uncertainty, and is chosen based on a trialand-error approach.

Application of our method requires that exhumation histories be discretized into a predefined, carefully chosen, number of time intervals. Time interval lengths should be short enough to suitably represent the temporal variations of interest without attempting to infer too many model parameters. With a short time interval length, parameter resolu- tion is reduced and the a priori information dominates. Conversely, as the time interval length increases, parameter resolution increases. However, the ability of the method to resolve changes in exhumation rate decreases. Therefore, time interval length should be chosen based on the age distribution.

\section{Conclusions}

The linear Gaussian inversion method presented here provides a practical, yet powerful tool to convert age information into exhumation rates. Our method generalizes the correlated concept of travel-time from a closure depth to the Earth's surface that is implicit in age-elevation relationships. In addition, it permits the simultaneous analysis of ages from different thermochronometric systems, provided their retention characteristics can be expressed in terms of first-order kinetics.

In addition to providing an estimate of exhumation rates, the formalisms of inverse theory provide associated measures of the quality of the exhumation rate estimates. These are in the form of covariance and resolution matrices. These matrices show that data variance, their geographic locations, a priori knowledge of exhumation rate, and the temporal distribution of the ages all play an important role in inferring exhumation rates.

We propose that our method is best suited to regional studies, where a general model for space and time variations in exhumation rate is desired. Given that the approach is linear, and the isotherms are calculated using an analytical solution, we can efficiently estimate exhumation rates across a range of wavelengths and timescales.

Acknowledgements. We would like to thank Jean Braun and Peter van der Beek for stimulating discussions throughout the development of the work. Thanks to Mark Brandon for his help with the topographic perturbation to the closure isotherms. Jeff Moore and Rebecca Reverman are thanked for reviews of the manuscript. Figures were prepared using the Generic Mapping Tools (Wessel and Smith, 1998).

Edited by: J. Braun

\section{References}

Backus, G. and Gilbert, F.: The resolving power of gross earth data, Geophys. J. Roy. Astron. Soc., 16, 169-205, 1968.

Backus, G. and Gilbert, F.: Uniqueness in the inversion of inaccurate gross earth data, Philosophical Transactions of the Royal Society of London, Series A, Mathemat. Phys. Sci., 266, 123-192, 1970.

Batt, G. E. and Braun, J.: On the thermomechanical evolution of compressional orogens, Geophys. J. Internat., 128, 364-382, 1997.

Batt, G. E. and Braun, J.: The tectonic evolution of the Southern Alps, New Zealand: insights from fully thermally coupled dynamical modelling, Geophys. J. Internat., 136, 403-420, 1999. 
Berger, A. L., Spotila, J. A., Chapman, J. B., Pavlis, T. L., Enkelmann, E., Ruppert, N. A., and Buscher, J. T.: Architecture, kinematics, and exhumation of a convergent orogenic wedge: A thermochronological investigation of tectonic/climatic interactions within the central St. Elias orogen, Alaska, Earth Planet. Sci. Lett., 270, 13-24, 2008.

Birch, F.: Flow of heat in the Front Range, Colorado, Geol. Soc. Am. Bull., 61, 567-630, 1950.

Blackwell, D. D., Steele, J. L., and Brott, C. A.: The terrain effect on terrestrial heat flow, J. Geophys. Res.h, 85, 4757-4772, 1980.

Blakely, R. J.: Potential theory in gravity and magnetic applications, Cambridge University Press, Oxford, 1996.

Brandon, M. T., Roden-Tice, M. K., and Garver, J. I.: Late Cenozoic exhumation of the Cascadia accretionary wedge in the Olympic Mountains, northwest Washington State, Geol. Soc. Am. Bull., 110, 985-1009, 1998.

Braun, J.: Quantifying the effect of recent relief changes on ageelevation relationships, Earth Planet. Sci. Lett., 200, 331-343, 2002.

Braun, J.: Pecube: a new finite-element code to solve the 3D heat transport equation including the effects of a time-varying, finite amplitude surface topography, Comput. Geosci., 29, 787-794, 2003.

Braun, J. and Robert, X.: Constraints on the rate of post-orogenic erosional decay from low-temperature thermochronological data: application to the Dabie Shan, China, Earth Surf. Proc. Landforms, 30, 1203-1225, 2005.

Braun, J., van der Beek, P., Valla, P., Robert, X., Herman, F., Glotzbach, C., Pedersen, V., Perry, C., Simon-Labric, T., and Prigent, C.: Quantifying rates of landscape evolution and tectonic processes by thermochronology and numerical modeling of crustal heat transport using PECUBE, Tectonophysics, 524, 1-28, 2012.

Bullard, E.: The Disturbance of the Temperature Gradient in the Earth's Crust by Inequalities of Height, Geophys. J. Internat., 4, 360-362, 1938.

Campani, M., Herman, F., and Mancktelow, N.: Two-and threedimensional thermal modeling of a low-angle detachment: Exhumation history of the Simplon Fault Zone, central Alps, J. Geophys. Res., 115, B10 420, doi:10.1029/2009JB007036, 2010.

Carlson, W. D., Donelick, R. A., and Ketcham, R. A.: Variability of apatite fission-track annealing kinetics; I, Experimental results, Am. Mineral., 84, 1213-1223, 1999.

Clark, S. P. and Jäger, E.: Denudation rate in the Alps from geochronologic and heat flow data, Am. J. Sci., 267, 1143-1160, 1969.

Dadson, S. J., Hovius, N., Chen, H., Dade, W. B., Hsieh, M. L., Willett, S. D., Hu, J. C., Horng, M. J., Chen, M. C., Stark, C. P., et al.: Links between erosion, runoff variability and seismicity in the Taiwan orogen, Nature, 426, 648-651, 2003.

Dodson, M. H.: Closure temperature in cooling geochronological and petrological systems, Contr. Mineral. Petrol., 40, 259-274, 1973.

Ducruix, J., Mouel, J. L. L., and Courtillot, V.: Continuation of Three-dimensional Potential Fields Measured on an Uneven Surface, Geophys. J. Roy. Astronom. Soc., 38, 299-314, 1974.

Ehlers, T. A., Willett, S. D., Armstrong, P. A., and Chapman, D. S.: Exhumation of the central Wasatch Mountains, Utah: 2. Thermokinematic model of exhumation, erosion, and ther- mochronometer interpretation, J. Geophys. Res.-Sol. Earth, 108, 2156-2202, 2003.

England, P. and Richardson, S.: The influence of erosion upon the mineral fades of rocks from different metamorphic environments, J. Geol. Soc., 134, 201-213, 1977.

Farley, K. A.: Helium diffusion from apatite: General behavior as illustrated by Durango fluorapatite, J. Geophys. Res., 105, 2903 2914, 2000.

Farr, T. G., Rosen, P. A., Caro, E., Crippen, R., Duren, R., Hensley, S., Kobrick, M., and Paller, M.: The Shuttle Radar Topography Mission, Rev. Geophys., 45, doi:10.1029/2005RG000183, 2007.

Fitzgerald, P. G. and Gleadow, A. J. W.: Fission-track geochronology, tectonics and structure of the Transantarctic Mountains in northern Victoria Land, Antarctica, Chem. Geol., 73, 169-198, 1988.

Fitzgerald, P. G., Sorkhabi, R. B., Redfield, T. F., and Stump, E.: Uplift and denudation of the central Alaska Range: A case study in the use of apatite fission track thermochronology to determine absolute uplift parameters, J. Geophys. Res., 100, 20175-20192, 1995.

Flowers, R. M., Ketcham, R. A., Shuster, D. L., and Farley, K. A.: Apatite (U-Th)/He thermochronometry using a radiation damage accumulation and annealing model, Geochimica et Cosmochimica Acta, 73, 2347-2365, 2009.

Franklin, J. N.: Well-posed stochastic extensions of ill-posed linear problems, J. Mathemat. Analys. Appl., 31, 682-716, 1970.

Gallagher, K.: Evolving temperature histories from apatite fissiontrack data, Earth Plane. Sci. Lett., 136, 421-435, 1995.

Gallagher, K.: Transdimensional inverse thermal history modeling for quantitative thermochronology, J. Geophys. Res., 117, 21562202, 2012.

Gallagher, K., Stephenson, J., Brown, R., Holmes, C., and Fitzgerald, P.: Low temperature thermochronology and modeling strategies for multiple samples 1: Vertical profiles, Earth Planet. Sci. Lett., 237, 193-208, 2005.

Gleadow, A. and Duddy, I.: A natural long-term track annealing experiment for apatite, Nuclear Tracks, 5, 169-174, 1981.

Glotzbach, C., van der Beek, P. A., and Spiegel, C.: Episodic exhumation and relief growth in the Mont Blanc massif, Western Alps from numerical modelling of thermochronology data, Earth Planet. Sci. Lett., 304, 417-430, 2011.

Grasemann, B. and Mancktelow, N. S.: Two-dimensional thermal modelling of normal faulting: the Simplon Fault Zone, Central Alps, Switzerland, Tectonophysics, 225, 155-165, 1993.

Green, P., Duddy, I. R., Laslett, G. M., Hegarty, K. A., Gleadow, A. J. W., and Lovering, J. F.: Thermal annealing of fission tracks in apatite 4. Quantitative modelling techniques and extension to geological timescales, Chem. Geol., 79, 155-182, 1989.

Green, P. F., Duddy, I. R., Gleadow, A. J. W., Tingate, P. R., and Laslett, G. M.: Fission-track annealing in apatite: track length measurements and the form of the Arrhenius plot, Nucl. Tracks Radiat. Measurem., 10, 323-328, 1985.

Grimmer, J. C., Jonckheere, R., Enkelmann, E., Ratschbacher, L., Hacker, B. R., Blythe, A. E., Wagner, G. A., Wu, Q., Liu, S., and Dong, S.: Cretaceous-Cenozoic history of the southern Tan-Lu fault zone: apatite fission-track and structural constraints from the Dabie Shan (eastern China), Tectonophysics, 359, 225-253, 2002. 
Harrison, T. M., Copeland, P., Kidd, W., Yin, A., et al.: Raising tibet, Science, 255, 1663-1670, 1992.

Harrison, T. M., Ryerson, F. J., Le Fort, P., Yin, A., Lovera, O. M., and Catlos, E. J.: A Late Miocene-Pliocene origin for the Central Himalayan inverted metamorphism, Earth Planet. Sci. Lett., 146, $1-7,1997$.

Herman, F., Rhodes, E., Braun, J., and Heiniger, L.: Uniform erosion rates and relief amplitude during glacial cycles in the Southern Alps of New Zealand, as revealed from OSLthermochronology, Earth Planet. Sci. Lett., 297, 183-189, 2010.

House, M. A., Wernicke, B. P., and Farley, K. A.: Dating topography of the Sierra Nevada, California, using apatite (U-Th)/He ages, Nature, 396, 66-69, 1998.

$\mathrm{Hu}, \mathrm{S}$., He, L., and Wang, J.: Heat flow in the continental area of China: a new data set, Earth Planet. Sci. Lett., 179, 407-419, 2000.

Jackson, D. D.: Interpretation of Inaccurate, Insufficient and Inconsistent Data, Geophys. J. Roy. Astronom. Soc., 28, 97-109, 1972.

Jeffreys, H.: The Disturbance of the Temperature Gradient in the Earth's Crust by Inequalities of Height, Geophys. J. Internat., 4, 309-312, 1938.

Ketcham, R. A., Donelick, R. A., and Carlson, W. D.: Variability of apatite fission-track annealing kinetics: III. Extrapolation to geological time scales, Am. Mineral., 84, 1235-1255, 1999.

Ketcham, R. A., Carter, A., Donelick, R. A., Barbarand, J., and Hurford, A. J.: Improved modeling of fission-track annealing in apatite, Am. Mineral., 92, 799-810, 2007.

Lees, C. H.: On the shapes of the isogeotherms under mountain ranges in radio-active districts, Proceedings of the Royal Society of London. Series A, Containing Papers of a Mathematical and Physical Character, 83, 339-346, http://www.jstor.org/ stable/92976, 1910.

Liu, S., Zhang, G., Ritts, B. D., Zhang, H., Gao, M., and Qian, C.: Tracing exhumation of the Dabie Shan ultrahigh-pressure metamorphic complex using the sedimentary record in the Hefei Basin, China, Geol. Soc. Am. Bull., 122, 198-218, 2010.

Mancktelow, N. and Grasemann, B.: Time-dependent effects of heat advection and topography on cooling histories during erosion, Tectonophysics, 270, 167-195, 1997.

Matheron, G.: Principles of geostatistics, Econom. Geol., 58, 12461266, 1963.

McQuarrie, N., Horton, B. K., Zandt, G., Beck, S., and DeCelles, P. G.: Lithospheric evolution of the Andean fold-thrust belt, Bolivia, and the origin of the central Andean plateau, Tectonophysics, 399, 15-37, 2005.

Molnar, P. and England, P.: Late Cenozoic uplift of mountain ranges and global climate change: chicken or egg?, Nature, 346, 29-34, 1990.

Moore, M. A. and England, P. C.: On the inference of denudation rates from cooling ages of minerals, Earth Planet. Sci. Lett., 185, 265-284, 2001.

Omar, G. I., Steckler, M. S., Buck, W. R., and Kohn, B. P.: Fissiontrack analysis of basement apatites at the western margin of the Gulf of Suez rift, Egypt: evidence for synchroneity of uplift and subsidence, Earth Planet. Sci. Lett., 94, 316-328, 1989.

Press, W. H., Teukolsky, S. A., Vetterling, W. T., and Flannery, B. P.: Numerical recipes in FORTRAN. The art of scientific computing, Cambridge: University Press, c1992, 2nd Edn., 1992.
Ratschbacher, L., Hacker, B. R., Webb, L. E., McWilliams, M., Ireland, T., Dong, S., Calvert, A., Chateigner, D., and Wenk, H. R.: Exhumation of the ultrahigh-pressure continental crust in east central China: Cretaceous and Cenozoic unroofing and the TanLu fault, J. Geophys. Res., 105, 13303-13338, 2000.

Reiners, P. W. and Brandon, M. T.: Using thermochronology to understand orogenic erosion, Annu. Rev. Earth Planet. Sci., 34, 419-466, 2006.

Reiners, P. W., Zhou, Z., Ehlers, T. A., Xu, C., Brandon, M. T., Donelick, R. A., and Nicolescu, S.: Post-orogenic evolution of the Dabie Shan, eastern China, from (U-Th)/He and fission-track thermochronology, Am. J. Sci., 303, 489-518, 2003.

Reiners, P. W., Spell, T. L., Nicolescu, S., and Zanetti, K. A.: Zircon (U-Th)/He thermochronometry: He diffusion and comparisons with ${ }^{40} \mathrm{Ar} /{ }^{39} \mathrm{Ar}$ dating, Geochimica et Cosmochimica Acta, 68, 1857-1887, 2004.

Schildgen, T. F., Balco, G., and Shuster, D. L.: Canyon incision and knickpoint propagation recorded by apatite ${ }^{4} \mathrm{He} /{ }^{3} \mathrm{He}$ thermochronometry, Earth Planet. Sci. Lett., 293, 377-387, 2010.

Shuster, D. L., Flowers, R. M., and Farley, K. A.: The influence of natural radiation damage on helium diffusion kinetics in apatite, Earth Planet. Sci. Lett., 249, 148-161, 2006.

Shuster, D. L., Cuffey, K. M., Sanders, J. W., and Balco, G.: Thermochronometry Reveals Headward Propagation of Erosion in an Alpine Landscape, Science, 332, 84, 2011.

Stephenson, J., Gallagher, K., and Holmes, C. C.: Low temperature thermochronology and strategies for multiple samples: 2: Partition modelling for 2D/3D distributions with discontinuities, Earth Planet. Sci. Lett., 241, 557-570, http://www.sciencedirect.com/science/article/ B6V61-4J022T3-1/2/723715442bc0c979bec22f09aa135035, 2006.

Stüwe, K. and Hintermuller, M.: Topography and isotherms revisited: the influence of laterally migrating drainage divides, Earth Planet. Sci. Lett., 184, 287-303, 2000.

Stüwe, K., White, L., and Brown, R.: The influence of eroding topography on steady-state isotherms. Application to fission track analysis, Earth Planet. Sci. Lett., 124, 63-74, 1994.

Sutherland, R., Gurnis, M., Kamp, P. J. J., and House, M. A.: Regional exhumation history of brittle crust during subduction initiation, Fiordland, southwest New Zealand, and implications for thermochronologic sampling and analysis strategies, Geosphere, 5, 409, 2009.

Tarantola, A.: Inverse problem theory and methods for model parameter estimation, Society for Industrial Mathematics, 2005.

Tarantola, A. and Nercessian, A.: Three-dimensional inversion without blocks, Geophys. J. Roy. Astronom. Soc., 76, 299-306, 1984.

Tarantola, A. and Valette, B.: Generalized nonlinear inverse problems solved using the least squares criterion, Rev. Geophys. Space Phys., 20, 219-232, 1982.

Thomson, S. N., Brandon, M. T., Reiners, P. W., Zattin, M., Isaacson, P. J., and Balestrieri, M. L.: Thermochronologic evidence for orogen-parallel variability in wedge kinematics during extending convergent orogenesis of the northern Apennines, Italy, Bull. Geol. Soc. Am., 122, 1160-1176, 2010.

Turcotte, D. L. and Schubert, G.: Geodynamics applications of continuum physics to geological problems, New York, NY (US); John Wiley and Sons, Inc., 1982. 
Valla, P. G., van der Beek, P. A., Shuster, D. L., Braun, J., Herman, F., Tassan-Got, L., and Gautheron, C.: Late Neogene exhumation and relief development of the Aar and Aiguilles Rouges massifs (Swiss Alps) from low-temperature thermochronology modeling and $4 \mathrm{He} / 3 \mathrm{He}$ thermochronometry, J. Geophys. Res., 117, F01004, doi:10.1029/2011JF002043, 2012.

Van den Haute, P.: Fission-track ages of apatites from the Precambrian of Rwanda and Burundi: relationship to East African rift tectonics, Earth Planet. Sci. Lett., 71, 129-140, 1984.

Vernon, A. J., van der Beek, P. A., Sinclair, H. D., and Rahn, M. K.: Increase in late Neogene denudation of the European Alps confirmed by analysis of a fission-track thermochronology database, Earth Planet. Sci. Lett., 270, 316-329, 2008.

Wagner, G. A. and Reimer, G. M.: Fission track tectonics: the tectonic interpretation of fission track apatite ages, Earth Planet. Sci. Lett., 14, 263-268, 1972.

Wagner, G. A., Miller, D. S., and Jäger, E.: Fission track ages on apatite of Bergell rocks from Central Alps and Bergell boulders in Oligocene sediments, Earth Plan. Sci. Lett., 45, 355-360, 1979.
Werner, D.: Geothermal problems in mountain ranges (Alps), Tectonophysics, 121, 97-108, 1985.

Wessel, P. and Smith, W. H. F.: New, improved version of Generic Mapping Tools released, Eos Transactions, 79, 579-579, 1998.

Willett, S. D.: Stochastic inversion of thermal data in a sedimentary basin: resolving spatial variability, Geophys. J. Internat., 103, 321-339, 1990.

Willett, S. D.: Inverse modeling of annealing of fission tracks in apatite 1: A controlled random search method, Am. J. Sci., 297, 939-969, 1997.

Willett, S. D. and Brandon, M. T.: On steady states in mountain belts, Geology, 30, 175-178, 2002.

Willett, S. D. and Brandon, M. T.: Some analytical methods for converting thermochronometric age to erosion rate, Geochem., Geophys., Geosystems, 2013.

Zeitler, P. K.: Cooling history of the NW Himalaya, Pakistan, Tectonics, 4, 127-151, 1985. 